This is the peer reviewed version of the following article: Cai, Z., Parker, S. K., Chen, Z., \& Lam, W. (2019). "How Does the Social Context Fuel the Proactive Fire? A Multi-level Review and Theoretical Synthesis." Journal of Organizational Behavior. 40, 209-320. https://doi.org/10.1002/job.2347 (ABDC A* Journal), which has been published in final form at https://doi.org/10.1002/ job.2347. This article may be used for non-commercial purposes in accordance with Wiley Terms and Conditions for Use of SelfArchived Versions.

\title{
How Does the Social Context Fuel the Proactive Fire? A Multi-level Review and Theoretical Synthesis
}

\begin{tabular}{|r|l|}
\hline Journal: & Journal of Organizational Behavior \\
\hline Manuscript ID & JOB-16-0781.R3 \\
\hline Wiley - Manuscript type: & The IRIOP Annual Review Issue \\
\hline Research Method Keywords: & \\
\hline Keywords: & proactive behavior, social context, multilevel, proactive motivation model \\
\hline
\end{tabular}

\section{SCHOLARONE \\ Manuscripts}




\begin{abstract}
The role of social context (e.g., leadership, team climate, organizational support) in shaping employee proactive behavior has received considerable attention and has been investigated across multiple forms of proactive behavior. However, the research has not been well integrated. In this review we adopt a multilevel approach to synthesize what is known about how social context factors influence employees' proactive behavior, as well as what mechanisms underpin these effects. Our analyses show that leader-, team-, and organizationrelated social context factors mainly influence employee proactivity through shaping "reason to," "can do," and "energized to" states (i.e., proactive motivational states) via individual-, team-, and cross-level processes. That has been most frequently investigated is the effect of the discretionary social context, particularly leadership, on proactive behavior. We also review the interaction effects between social context factors and other factors on employee proactive behavior and found inconsistent support for the motivational-fit perspective that stimuli with the same directions enhance each other's effect. We offer a research agenda to advance theoretical insights on this important topic.
\end{abstract}

Keywords: social context, proactive behavior, multilevel, proactive motivation model 
Running Head: Social Context and Proactive Behavior

\section{How Does the Social Context Fuel the Proactive Fire?}

\section{A Multi-level Review and Theoretical Synthesis}

Given its positive implications for enhancing individual and organizational effectiveness, a fast-growing body of literature has focused on employee work-based proactive behavior, or employees' self-initiated efforts to bring about future-focused changes (Parker \& Collins, 2010). Aiming to change and improve the situation or oneself (Bindl \& Parker, 2017; Parker, Williams, \& Turner, 2006), a fundamental component of proactivity ${ }^{1}$ is the idea that people do not passively accept environmental exigencies but instead can intentionally take actions to change the work environment they encounter (Parker \& Collins, 2010).

Existing literature has mainly examined why proactive behavior happens in the workplace, identifying a variety of individual attributes and job features, such as proactive personality and job autonomy, as antecedents (for reviews, please see by Marinova, Peng, Lorinkova, Van Dyne, \& Chiaburu, 2015; Ohly \& Schmitt, 2017; and Wu \& Li, 2017). However, as individauls become more independent on each other in the workplace (Grant \& Parker, 2009; Griffin, Neal, \& Parker, 2007), to affect the environment and initiate changes, employees need to seek support from, cooperate with, and build allies with others. Indeed, an interactionist perspective on proactivity would assume that the social context shapes individual decisions to be proactive. Simply stated, "Interactionism notes that the person, environment, and behavior continuously influence one another" (Crant, Hu, \& Jiang, 2017, p.194). Consistent with such a perspective, in recent years there has been an increase in studies focusing on social factors as antecedents to work-based proactive behavior (e.g., Hong, Liao, Raub, \& Han, 2016; Parker et al., 2006).

\footnotetext{
${ }^{1}$ In this paper, we use proactive behavior and proactivity interchangeably.
} 
Despite the growth in research focusing on the role of social processes, there is a lack of clarity about the full set of social context factors that might shape multiple forms of proactive behavior. First, most scholars have focused on a single social context variable at a time. For example, Parker and $\mathrm{Wu}$ (2014) examined how leadership affects proactive behavior, but did not consider other social processes. Thus, we need to develop a clearer picture of the full range of social context factors that affect proactive behavior. Second, when research has considered multiple social factors, it has tended to do so for just one form of proactivity. For instance, Ng and Feldman's (2012) meta-analysis identified a set of social factors that shape employee voice behavior. Supporting a resource-conservation argument (Hobfoll, 1986), the authors concluded that social stressors decrease voice behavior. However, although their study reviewed multiple social antecedents, it focused only on voice behavior, so we do not know if different sorts of social context variables are needed depending on the form of proactive behavior. Third, the level of the social context variable has received little attention. For example, Farrell and Strauss (2013) proposed a model of how work-based social relationships affect proactive behavior but they did not consider the possibility that these relationships could vary across different levels, such as leader-member exchange (LMX) at a leader-subordinate level and team support at a team level. Accordingly, the multilevel nature of social context factors was obscured. Thus there is a need to synthesize research on the multilevel set of social context factors that shape different types of proactive behaviors (Chen, Farh, Campbell-Bush, Wu, \& Wu, 2013; Chen \& Kanfer, 2006).

Once we identify the social context antecedents for employee proactive behavior, this paves the way for recognizing the mechanisms that underlie social cues for proactive behavior. For example, Detert and Burris (2007) found that transformational leadership influences individual voice behavior through psychological safety, whereas Liu, Zhu, and Yang (2010) found social and relational identification to be the mechanisms. Further 
investigation is needed to synthesize the mediating mechanisms that influence proactive employee behavior (Chiaburu, Lorinkova, \& Van Dyne, 2013).

Our review has three major purposes. First, we identify different social context factors across multiple proactive behavior domains to clarify the association between the social context and proactive behavior. Second, we adopt an integrated approach to summarize the mediating mechanisms for the impact of social context predictors on proactive behavior, spelling out multilevel pathways to understand why and under which circumstances employees engage in proactive behavior. Finally, we offer a research agenda to build on what is known as well as to further advance theoretical insights on this topic.

\section{Domain and Scope of the Review: Social Context and Proactive Behavior}

In what follows, we define what we mean by social context and proactive behavior, and then describe how we identified papers linking these concepts for the review.

\section{Clarifying Social Context}

The notion of "context" was originally conceptualized as the stimuli and phenomena surrounding individuals that "illuminate" their behaviors (Cappelli \& Sherer, 1991), implying a moderating role of context for shaping behavior. Later, scholars developed an extended meaning of context, identifying it as a predictor of behavior. Mowday and Sutton (1993) argued that the context serves as opportunities and constraints for behaviors in organizational settings. Bamberger (2008) recognized that context is both a moderator and a predictor of behavior, defining it as "surrounding phenomena or temporal conditions that directly influence lower-level phenomena and condition relations between one or more variables at different levels of analysis" (p. 841). Building on this perspective, Johns (2018) pointed out that context "provides constraints and opportunities that affect the occurrence of organizational behavior and shape its meaning" and defined context as "situational or 
environmental stimuli that impinge upon focal actors and are often located at a different level of analysis from those actors" (p. 22).

Guided by this literature, we recognize social context as both a predictor of proactive employee behavior, and a moderator of the relationship between other factors and proactive behavior. We follow Johns (2018) to define the social context as the multi-level interpersonal stimuli that surround, and are external to, the individual(s). This definition encompasses a broad scope of interpersonal stimuli. Thus, besides direct interpersonal interactions and relationships, such as coworker support and leader-member exchange, the social context also includes leaderships, team climates, organizational values, industry norms, and national values. Collective values and norms are social factors relevant to employee work-based proactive behavior because they emerge from the interactions among individuals who are involved in the particular context. These interactions frequently provide diagnostic cues and criteria against which individuals interpret and evaluate their own behaviors and others'.

By focusing on social context as being "multilevel," we recognize that social factors can differ in levels of theorization, measurement, and analysis. Leadership, for example, has been measured and analyzed at both individual and team levels, with the former reflecting individuals' perceptions of their leaders, and the latter reflecting the teams' shared perception of the leader (Chen \& Bliese, 2002). In their multilevel model of team motivation, Chen and Kanfer (2006) differentiate discretionary inputs, or person-oriented stimuli directed toward a specific individual (an individual-level process), from ambient inputs, or team-oriented stimuli that pervade the team as a whole (a team-level process). Similarly, we adopt a multilevel perspective and classify the social context into discretionary social context factors and ambient social context factors. Discretionary social context factors are usually theorized, measured, and analyzed at the individual level, reflecting individual social experiences or perceptions of the social context, such as perceived leadership and LMX. Ambient social 
context factors function at higher levels, reflecting social experiences or shared properties common to collectives, such as team leadership, team climate, and LMX diversity.

\section{Clarifying Proactive Behavior}

Proactive behavior refers to self-initiated behavior to bring about future-focused change (Parker et al., 2006). There are many forms of individual-level proactive behavior that have received attention in the literature. We include all of these forms of proactivity in the current review. We draw on Parker and Collins (2010), who synthesized the many forms into three overarching categories: (1) proactive work behavior, including taking charge, innovative behavior, voice, and problem prevention; (2) proactive strategic behavior, including issue selling and strategic scanning; and (3) proactive person-environment fit behavior, including feedback seeking and job change negotiation (idiosyncratic deals).

Recently scholars have proposed that we should focus on team-level proactive behavior because "to overcome and thrive in such uncertainty ... teams must be proactive" (Harris \& Kirkman, 2017). Williams, Parker, and Turner (2010) argue that team proactive behavior is a team-level concept that is theoretically similar to individual proactive behavior and define it as "the extent to which a team engages in self-starting, future-focused action that aims to change the external situation or the team itself" (p. 302). To capture these multilevel phenomena, we include studies with team proactive behavior in this review. ${ }^{2}$

\section{Review Methodology}

We searched for empirical papers in the fields of business, management, and applied psychology using keywords related to proactive behavior, including: (1) generic terms relevant to proactive behavior, such as proactivity, proactive behavior, personal initiative, and change-oriented citizenship, and (2) specific types of proactive behavior, including

\footnotetext{
${ }^{2}$ Note that, although the terms are similar, team member proactive behavior (Griffin et al., 2007; see also interpersonal proactive behaviors, Belschak \& Den Hartog, 2010) is distinct from "team proactive behavior" because the former is a kind of individual-level proactivity that are directed to team goals, such as individually introducing new methods to enhance the team's processes.
} 
taking charge, innovative behavior, voice, problem prevention, issue selling, strategic scanning, feedback seeking, and job change negotiation (idiosyncratic deals). We only focused on top-tier journals in our review to ensure the quality of the studies. We made the selection mainly based on the journal impact factors $(>2)$. The final list of journals (see Online Supplement Appendix 1) is similar to the list of core top management journals identified by Podsakoff, MacKenzie, Podsakoff, and Bachrach (2008), so we think this list is reasonable.

Using the keywords, we first searched for literature mainly from the Web of Science, complemented by EBSCO and PsycINFO. We also manually checked the reference list in previous book chapters, qualitative reviews, and meta-analyses about proactive behavior. This procedure resulted in approximately 400 papers. Those papers published in the listed journals were retained for the next steps. We then checked whether social context factors were considered in these papers. Those that included social factors, either as predictors or moderators, were retained. This procedure led us to identify 152 related papers.

To organize the findings, we coded the studies in the following way. After classifying the social context factors according to subject (i.e., leader-related, team-related, and organization-related), we coded whether they shaped and affected proactive behavior (as antecedents) or whether they conditioned the relationship between other factors and proactive behavior (as moderators). For the studies focusing on the interaction between social context factors, we coded the factors as "moderators" or "antecedents" according to the authors' propositions. Then, we classified the social factors by themes. For example, ethical leadership and empowering leadership were coded as describing leadership styles. Team-initiative climate and team-voice climate were coded as describing team climates. Third, we coded the factors as being either ambient or discretionary, according to the criteria described above. 
Finally, for each study that included a mediating process between social context and proactive behavior, we coded the mediators according to the process they described. Having created a list of all mediating processes, we then sought to categorize them in a meaningful way. Because our focus was on proactive behavior, and most of the processes were motivational (e.g., intrinsic motivation, self-efficacy), we applied the proactive motivation model proposed by Parker, Bindl, and Strauss (2010). Approximately $80 \%$ of the identified mediators fit this model, which identifies three kinds of proactive motivational states that lead to proactive behavior: "can do," including "self-efficacy perceptions (can I do it?), control appraisals and attributions (e.g., how feasible is it?), and the perceived costs of action (e.g., how risky is it?)" (p. 834); "reason to," which is about goal selection and persistence, especially self-determination motivation; and "energized to," the "'hot' affect-related motivational states (p. 838). Approximately $20 \%$ of the mediators could not readily be classified into a single proactive motivation state (e.g., work engagement, psychological empowerment); these were coded as "other."

In what follows we discuss the results of the review, focusing first on the studies in which social context is an antecedent of proactive behavior, then on the studies that examine the interaction effects with social context on proactive behavior.

\section{Social Context Factors as Antecedents of Proactive Behavior}

The key findings from studies investigating social context factors as antecedents of proactive behavior are summarized in Online Supplement Figure 1. As the figure shows, most studies $(\mathrm{N}=94)$ are about leader-related factors; 29 studies include team-related factors, and 24 include organization-related factors. We found no studies that considered industryrelated or country-related factors. We discuss each set of factors in turn. 


\section{Leader-Related Factors as Antecedents of Proactive Behavior}

Existing research shows that leadership styles, specific leadership behaviors, and the quality of the relationship with leaders have significant influences on proactive behavior.

Leadership Styles. Transformational leadership emphasizes the leader's role in introducing and implementing changes through creating a challenging vision, stimulating subordinates' intellect, and inspiring them to go beyond expectations (Den Hartog \& Belschak, 2012). Since proactive behavior aims to bring about changes, it is not surprising that transformational leadership has been found to be a powerful driver of this behavior (Den Hartog \& Belaschak, 2017). In our review, its correlation with individual proactive behavior ranged from .06 (Niessen, Mäder, Stride, \& Jimmieson, 2017) to .51 (Kuonath, Specht, Kühnel, Pachler, \& Frey, 2017), although most studies showed a correlation between .20 and .40 (e.g., Den Hartog \& Belschak, 2012; Schmitt, Den Hartog, \& Belschak, 2016).

"Can do" and "reason to" motivational states were found to mediate the relationship between discretionary transformational leadership and individual proactivity. With respect to “can do," transformational leaders were found to increase subordinates' self-efficacy for carrying out a broader set of work tasks (role-breadth self-efficacy) and to lower their perceived risk of speaking up (psychological safety) (Detert \& Burris, 2007; LópezDomínguez, Enache, Sallan, \& Simo, 2013). With respect to "reason to", these leaders increase subordinates' affective commitment (Strauss, Griffin, \& Rafferty, 2009), identification (Liu, Zhu, \& Yang, 2010), and voice role perception (Duan, Li, Xu, \& Wu, 2017). These "can do" and "reason to" motivational states, in turn, increase individual proactive behavior. Interestingly, Walumbwa and Hartnell (2011) found that ambient transformational leadership increased subordinates' relational identification, which then affected individual proactive behavior through role-breadth self-efficacy (RBSE), suggesting that "reason to" motivation sometimes drives "can do" motivation. 
There is also some evidence that "energized to" motivational states are mediators. By satisfying psychological needs and providing meaning, importance, and support, transformational leaders, as discretionary stimuli, were found to foster subordinates' thriving and work engagement (“other”) (Niessen et al., 2017; Schmitt et al., 2016), which arguably provide positive and activated affective states that stimulate proactive behavior.

Empowering leadership differs from transformational leadership in that it explicitly encourages autonomy, control, and independence (Lee, Willis, \& Tian, 2018). It has been found to positively shape proactivity, which is not surprising given that proactive behavior is self-initiated. The correlations with individual proactive behavior ranged from .16 (Chen et al., 2011) to .53 (Martin, Liao, \& Campbell, 2013), with most studies reporting it to be approximately .20 (e.g., Li, Chiaburu, Kirkman, \& Xie, 2013; Raub \& Robert, 2010).

As to why empowering leadership is important, both affective commitment ("reason to") and RBSE (“can do") have been shown to mediate the top-down effect of ambient empowering leadership on individual proactive behavior (e.g., Chen, Sharma, Edinger, Shapiro, \& Farh, 2011; Li, He, Yam, \& Long, 2015). Interestingly, Hong et al. (2016) found that when simultaneously examining the mediation effects of RBSE ("can do"), intrinsic motivation ("reason to"), and positive affect (“energized to"), only RBSE was significant. They suggested that the insignificance of "reason to" and "energized to" motivational states might be because these two states could be better measured in other ways and there are unexamined moderators. However, the significance of RBSE suggests that it might be a more important mediator than the other two, at least for this top-down effect.

As might be expected, psychological empowerment (“other"), or a high sense of impact, meaningfulness, and self-determination, was found to be a significant mediator. For example, Chen et al. (2011) and Raub and Robert (2010) found that ambient and discretionary empowering leadership positively affected individuals' psychological 
empowerment, which in turn influenced individual proactive behavior. At the team level, Kirkman and Rosen (1999) found that ambient empowering leadership influenced team proactive behavior through team psychological empowerment.

Ethical leadership is different from transformational leadership and empowering leadership in that it does not specifically emphasize motivating employees but focuses on doing things in the "right way" (Brown, Treviño, \& Harrison, 2005). Its correlation with individual proactive behavior was at a similar level to other leadership styles, ranging from .19 (Kalshoven, Den Hartog, \& de Hoogh, 2013) to .48 (Chen \& Hou, 2016).

As to why ethical leadership fosters proactivity, most evidence suggests that this way of leading builds "reason to" motivational states, including intrinsic motivation (Tu \& Lu, 2013), identification (Zhu, He, Treviño, Chao, \& Wang, 2015), and a motivation for reciprocity (Kalshoven et al., 2013). For example, Tu and Lu (2013) found that both discretionary and ambient ethical leadership influenced individual innovative behavior through individual intrinsic motivation. Moreover, since ambient ethical leadership increases team members' understanding of the social impact of their jobs and helps build relationships of trust among team members, it could influence team intrinsic motivation, in turn affecting individual innovative behavior. One study, by Walumbwa and Schaubroeck (2009), found that ambient ethical leadership increased team psychological safety ("can do") because ethical leaders, through showing openness and truthfulness to subordinates, lower individuals" perceived risk of speaking up. Regarding the "energized to" pathway, Den Hartog and Belschak (2012) found that ethical leaders increased individuals' work engagement, indicating a positive emotional state that inspires proactive behavior.

Although these three kinds of leadership are the most extensively studied ones with respect to proactive behavior, scholars have examined the effects of other leadership styles, such as servant leadership (Panaccio, Henderson, Liden, Wayne, \& Cao, 2015), authentic 
leadership (Liang, 2017), paternalistic leadership (Zhang, Huai, \& Xie, 2015), and selfsacrificial leadership (He, Zhou, Long, Huang, \& Hao, 2018). These studies consistently showed, with correlations ranging from .18 to .40 , that leaders displaying positive forms of leadership can facilitate individual proactive behavior. Interestingly, scholars have also shown that leadership can be deleterious to proactive behavior. Abusive supervision, which refers to individuals' perception that their leaders continuously engage in hostile verbal or nonverbal behaviors (Tepper, Simon, \& Park, 2017), was found to be negatively related to individual proactive behavior, with correlations ranging from -.22 (Farh \& Chen, 2014) to -.12 (Ouyang, Lam, \& Wang, 2015). This kind of supervision psychologically detaches individuals from their organizations (Burris, Detert, \& Chiaburu, 2008), which essentially impairs "reason to" motivation, and lowers individuals' judgment of their own self-worth (perceived insider status, Ouyang et al., 2015; organization-based self-esteem, Farh \& Chen, 2014), which implies lower "can do" motivation. Furthermore, Farh and Chen (2014) found that due to a process of social comparison, when ambient abusive supervision was low, discretionary abusive supervision had an even more negative influence on individuals' organization-based self-esteem (OBSE), because they perceived that the abuse was highly individualized.

Specific Leader Behaviors. Besides general leadership styles, scholars have also focused on leaders' specific behaviors to understand their impacts on employee proactive behavior.

Leaders can increase employee proactive behavior by directly encouraging change, including providing a clear vision (Griffin, Parker, \& Mason, 2010), signaling that they welcome and are interested in employees' ideas (Bienefeld \& Grote, 2014), asking employees for suggestions (Tangirala \& Ramanujam, 2012), and actively responding to employees’ innovative inputs (Janssen \& Gao, 2015). These correlations with individual proactivity range 
from .11 to $.46 .{ }^{3}$ Psychological safety ("can do"; Bienefeld \& Grote, 2014), perceived status (“other"; Janssen \& Gao, 2015), and perceived influence (“other"; Tangirala \& Ramanujam, 2012) were found to be the mediators. Note that perceived status and influence were argued to prompt individual proactive behavior because they make individuals feel they have the capacity ("can do") and responsibility ("reason to") to do so.

Leaders can also facilitate proactive behavior by treating employees in a considerate and respectful manner. Perceived leader support refers to individuals' perception that their leaders care about and value them and show support for their efforts (Chen, Li, \& Leung, 2016; Wu \& Parker, 2017). Its correlation with individual proactive behavior ranged from .13 (Parker et al., 2006) to .58 (Wu \& Parker, 2017), although most studies reported a correlation between .20 and .40 . Highly supportive leaders facilitate individual proactive behavior by making individuals feel that they could overcome obstacles when initiating changes, thus increasing their RBSE ("can do"; Wu \& Parker, 2017), and that their work is meaningful and joyful, thus increasing their intrinsic motivation ("reason"; Chen et al., 2016).

Delegating important tasks and decision responsibilities to subordinates (delegation; $r$ $=.18$, Chen \& Aryee, 2007) and treating them fairly (perceived leader justice; $r=.55$, McAllister, Kamdar, Morrison, \& Turban, 2007) were also found to be beneficial to individual proactive behavior. ${ }^{4}$ Interestingly, Liao and Chun (2016) found that observational monitoring behavior (gathering information about subordinates' work without direct input from them) and interactional monitoring behavior (gathering information directly from subordinates) have contrasting effects on individual proactive behavior. The reason is that the former indicates a lack of interaction during the information collection process, and makes

\footnotetext{
${ }^{3}$ One exception is that in sample 3 Bienefeld and Grote (2014) reported the correlation between leader inclusiveness and employee speaking up behavior to be -.11 , which is not significant.

${ }^{4}$ In this paper, $r$ is the correlation between the social context factor and proactive behavior in the corresponding study.
} 
subordinates feel less empowered, fearful, and skeptical; while the latter creates opportunities for open discussion that help build trusting relatonships.

Not all leaders' behaviors are positive. Leaders showing arrogance to subordinates were found to have a negative impact on employees' feedback-seeking behavior, likely because seeking feedback from such belittling leaders is risky and the outcome in uncertain $(r$ $=-.15$, Borden, Levy, \& Silverman, 2018). Leaders showing verbal aggression (e.g., making derogatory remarks and using harsh language) to subordinates were also found to decrease their feedback-seeking behavior because employees appraise experiences with rude leaders as negative affective events ( $r=-.04$, Nifadkar, Tsui, \& Ashforth, 2012).

While all the above studies treat leaders' behaviors as discretionary inputs, Schraub, Michel, Shemla, and Sonntag (2014) conceptualized leaders' emotional management as an ambient input. Based on affective event theory, they found that when leaders positively regulate team members' emotions, members were likely to have high job-related affective well-being (e.g., being happy, inspired; "energized to"), which inspired proactive behaviors ( $r$ =.21). Also, Rofcanin, Las Heras, Bal, Van Der Heijden, and Erdogan (2018) found that leaders' idiosyncratic deals were positively related to subordinates' $(r=.23)$. On the other hand, Frazier and Bowler (2015) found that ambient supervisor undermining decreased team voice climate and hence team voice itself because it highlights the risk of making challenging suggestions ("can do"; $r=-.27$ ).

Relationship with the Leader. Leadership scholars have argued that apart from focusing on what leaders do, it is important to adopt a relational perspective to concentrate on the relationships between individuals and their leaders (e.g., Lord, Gatti, \& Chui, 2016). In proactive behavior research, scholars have mainly examined the effect of leader-member exchange (LMX), which describes the relationships between leaders and followers as characterized by mutual trust and respect. Its correlation with individual proactive behavior 
ranges from -.09 (Ward, Ravlin, Klaas, Ployhart, \& Buchan, 2016) to .50 (Van Dyne, Kamdar, \& Joireman, 2008).

Proactive motivational states have been found to mediate the relationship between LMX and individual proactive behavior. For example, Burris et al. (2008) found that low LMX made employees psychologically detach from their organizations ("reason to"), thus performing less voice behavior. Based on broaden-and-build theory (Fredrickson, 2001), Lin, Kao, Chen, and Lu (2016) found that LMX influenced taking charge through positive affect (“energized to"). Yuan and Woodman (2010) theorized that LMX influences individual innovative behavior through expected image and performance gain ("can do"). Surprisingly, however, they found that perceived image gain had a negative effect on innovative behavior. The authors explained that these individuals are more focused on showing off or pleasing others to create a positive impression, which makes them actually less innovative. This finding echoes Strauss and Parker's (2014) proposition that proactive behavior elicited by extrinsic motivations is less effective.

Scholars have expanded the focus on LMX in three ways. First, they compared LMX with a similar concept, guanxi. Zhang, Li, and Harris (2015) argued that guanxi more describes the relationships developed after working hours and outside the work domain, and is relevant in workplaces where subordinates are very dependent on their leaders. These researchers proposed that guanxi is more important than LMX to proactive behavior because LMX is rooted in work-related exchanges that emphasize helping each other within the status quo, whereas guanxi affords long-term psychological safety and thus reduces the short-term risk of challenging the status quo. This proposition was supported with a sample of Chinese employees: while subordinate-rated guanxi and LMX had comparable correlations with taking charge $\left(r_{\text {guanxi }}=.22, r_{L M X}=.21\right)$, in the regression model, the coefficient of guanxi was significant $(\beta=.24, p<.01)$ but that of LMX was not $(\beta=.06, n s)$. 
Second, scholars have focused on LMX differentiation in teams, which describes the extent to which team members have different levels of exchange with their leaders. Chen, He, and Weng, (2018) found that LMX differentiation had a negative impact on team proactive behavior, but this effect became weaker when the differentiation was based more on individuals' task performance and organizational citizenship behavior. Third, the effect of exchange relationships with higher-level leaders have been examined. Liu, Tangirala, and Ramanujam (2013) found that employees' exchange relationship with skip-level leaders increased employees' voice to the skip-level leader. They found that this effect was stronger when employees' direct leaders did not have the resources to solve individuals' concerns, as depicted by a low exchange relationship between direct leaders and skip-level leaders.

Other Leader-related Factors. There are some other factors that were found to influence employee proactive behavior, including leaders' personal attributes (openness to change; $r=.45$, Tröster \& Van Knippenberg, 2012; self-efficacy; $r=.17 \& .20$, Fast, Burris, $\&$ Bartel, 2014; authentic personality; $r=.17$, Liang, 2017; narcissism; $r=.01$, Liu, Ting-Ju Chiang, Fehr, Xu, \& Wang, 2017), affect (positive affect; $r=.19$, Liu, Song, Li, \& Liao, 2017; negative affect; $r=-.07$, Pan \& Lin, 2018), and job embeddedness ( $r=.33$ to $47 ; \mathrm{Ng} \&$ Feldman, 2013). Proactive motivations were found or implied to be mediators in most of these studies. For example, based on the affect-as-social-information model (Van Kleef, De Dreu, \& Manstead, 2010), Liu et al. (2017) found that during an interaction episode, when leaders display positive affect, individuals' positive affect (“energized to") increased. This positive affect, in turn, informed individuals that the environment was safe (described by psychological safety) so that they made more voice to their leaders.

Summary of Leader-related Factors. Much attention has been given to leaders as significant others who shape individual proactivity (see Online Supplement Figure 2 for a summary). Positive leadership styles (e.g., transformational leadership), specific behaviors 
(e.g., vision), and a high-quality relationship between employees and leaders (e.g., LMX) have been found to be positively related to proactive behavior. From simple correlation statistics, we found that positive leadership styles and leader behaviors have similar effect sizes on individual proactive behavior, mostly around .20 to .40 . However, there are sometimes associations greater than .50 (e.g., Kuonath et al., 2017), suggesting quite powerful effects. In the case of LMX, there is a large range of associations, suggesting potential moderators of the relationship between this social context factor and individual proactive behavior. Of course, leaders can behave negatively too, and studies showed that such negative behaviors discouraged individual proactive behavior, revealing the "dark" side of some leaders.

In terms of why leadership matters, there is a body of clear evidence that "reason to" and "can do" motivational states serve as the primary mediators between leader-related factors and individual proactive behavior. In comparison, the mediating role of "energized to" motivational states has not been examined extensively. Individuals' judgments of self-worth, such as their OBSE and perceived influence, were also mediators (“other"). It is important to note that scholars have theorized the relationship between these judgments and proactive behavior by arguing for their influence on proactive motivation. For example, Tangirala and Ramanujam (2012) argued that perceived influence brings individuals a sense of responsibility to make constructive suggestions, which can be seen as a "reason to" motivational state.

One insight from this review is that most studies have treated leader-related factors as discretionary factors in their models. This discretionary focus is perhaps misplaced because it reflects individuals' perception, so it is not known whether leaders' behavior, or the way individuals construct these behaviors, is what influences individuals' proactive behavior. Indeed, the studies that treated leader-related factors as team-level inputs (ambient factors) 
found similar mediators to those that treated them as discretionary inputs, suggesting that ambient and discretionary factors influence individual proactive behavior through similar mechanisms. Overall, only a few studies have focused on how ambient leader-related factors influence team proactive behavior, so our understanding of the team-level paths linking leadership to proactivity are still very preliminary.

\section{Team-Related Factors as Antecedents of Proactive Behavior}

Compared with leaders ( $\mathrm{N}=94$ studies), teams have not received as much attention in the proactive behavior literature $(\mathrm{N}=29)$. From our review, we found that scholars mainly focused on the effects of team climate and interpersonal interactions with coworkers.

Team Climate. Team climate describes the shared perception of the way things are going and how things are done in teams (Reichers \& Schneider, 1990). In theory, it should be an ambient factor that pervades the team as a whole, although some scholars have argued that perceived team climate, as a discretionary factor that only affects individuals, could reflect individuals' cognitive interpretation of the team environment (e.g., Scott \& Bruce, 1994). Consequently, we include team climate as both an ambient and discretionary factor in this review.

Proactive-behavior-related climates, including initiative climate (Baer \& Frese, 2002; Raub \& Liao, 2012), voice climate (Morrison, Wheeler-Smith, \& Kamdar, 2011), and innovation climate (Morrison \& Phelps, 1999), describe the perception of whether proactive behavior is encouraged, safe, and supported in the team. ${ }^{5}$ Correlations of these climates with individual proactive behavior ranges from $-.01^{6}$ (Chen \& Hou, 2016) to .34 (Montani, Odoardi, \& Battistelli, 2014). In the two studies with team-level proactive behavior as the outcome, the correlations were .30 (Frazier \& Bowler, 2015) and .37 (Raub \& Liao, 2012).

\footnotetext{
${ }^{5}$ Voice climate also includes the shared belief that the team could voice effectively (Morrison et al., 2011).

${ }^{6}$ This is a correlation between perceived innovation climate and voice and is not significant.
} 
"Can do" and "reason to" motivational states were the main mediators of the effects of proactive behavior-related climates. For instance, based on the proactive motivation model (Parker et al., 2010), Hong et al. (2016) ${ }^{7}$ argued that initiative climate would increase personal initiative through RBSE, intrinsic motivation, and positive affect. But as mentioned above, only RBSE was a significant mediator. Choi (2007) found somewhat parallel effects: discretionary innovation climate influenced individual proactive behavior through individuals' felt responsibility for change ("reason to") and psychological empowerment, and ambient innovation climate had a top-down effect on individual proactive behavior through teams' felt responsibility for change ("reason to") and psychological empowerment ("other").

Some scholars have focused on climates that are not directly related to proactive behavior and have found that these climates have a positive effect. These correlations with individual proactivity ranged from .05 to .19. Axtell et al. (2000) found that perceived psychological safety climate increased innovative behavior, because it signals that there is a low risk in taking initiative. Wallace, Butts, Johnson, Stevens, and Smith (2016) found that an ambient involvement climate (in which the team encourages employee commitment by sharing information and power, encouraging self-development, and rewarding contributions), through satisfying individuals' basic psychological needs, improves their thriving (“other") and hence their innovative behavior. These two studies, respectively, suggest that "can do" and "energized to" motivational states serve as mediators. Finally, Lin and Leung (2014) found that an ambient procedural justice climate increased team identification ("reason to"), which in turn motivated employees to engage in innovative behavior.

Interpersonal Interactions with Coworkers. Along with how employees perceive their team environment, as captured by team climate, how team members interact with each other

\footnotetext{
${ }^{7}$ Hong and colleagues examined the effect of a department-level climate. But since they treated the department level as being only one level above the individual level, we include this study here.
} 
also has a great influence on their individual behaviors (Chen \& Kanfer, 2006; Chiaburu \& Harrison, 2008). During these interactions, members collect information, exchange resources, and alter their behaviors according to the feedback they receive.

There is a body of strong evidence proposing that favorable interaction with coworkers prompts both individual and team proactive behavior. The correlation of this factor with individual proactivity ranges from .01 to .44 ; the correlation with team proactivity ranges from .44 to .80 . For example, as a discretionary input, the perceived trust gained from coworkers was found to motivate individuals to take the risk of setting and striving for broader goals than their prescribed job requirements, as described by a flexible role orientation ("reason to"), which in turn improved their proactive behavior (Parker et al., 2006). In a similar vein, the perception of coworker support for safety was found to motivate individuals to reciprocate with a more frequent voice concerning safety (Tucker, Chmiel, Turner, Hershcovis, \& Stride, 2008).

At the team level, when team members treat each other with respect and trust, as depicted by favorable interpersonal norms, the team is likely to engage in collective proactive behavior, arguably because of the low perceived risk and high perceived favorability of initiating changes (Williams et al., 2010). Brav, Andersson, and Lantz (2009) found that team cooperation increased team proactive behavior because it encourages team members to take on minor dissent to initiate changes. Team support also was found to increase team proactive behavior because it encourages risk-taking behaviors. These authors examined the possibility that team reflexivity - a cognitive factor describing team members collectively reflecting upon and adapting their objectives, strategies, processes, and wider objects (West, Hirst, Richter, \& Shipton, 2004) - could increase team proactive behavior because it encourages team members to make constructive criticism and actively deal with the conflicting 
perspectives. However, they did not find a significant effect, admitting that their measure of reflectivity might be problematic and encouraging more studies on this factor.

By way of contrast, team conflict, an important variable in team-level research (Mathieu, Maynard, Rapp, \& Gilson, 2008), was found to be negatively related to proactive behavior. The correlations with individual proactivity ranged from -.14 to -.05. Chen et al. (2011) treated relationship conflict as a demotivating force for the team and argued that it has a negative effect on individual innovative behavior through reducing affective commitment ("reason to") and psychological empowerment (“other"). In Chen's (2011) first study, this proposition was supported. However, in the second, neither mediation path was significant. This might be because the effects were dependent on empowering leadership (Chen et al., 2011). Contrary to Chen et al., Schraub et al. (2014) found that team task conflict, rather than team relationship conflict, had a negative top-down effect on individual personal initiative through affective job-related well-being ("energized to"). They argued that this is because of the high correlation between these two types of conflicts. More studies are needed to fully understand the effect of team conflict on proactive behavior.

It is worth noting that Lee, Duffy, Scott, and Schippers (2018) found that being envied by coworkers had a double-edged effect on proactive behavior: it was positively related to both positive mood (e.g., active, enthusiastic, proud) and negative mood (e.g., jittery, nervous, distressed), which influenced proactive behavior through work engagement. Scott and Bruce (1994) did not find a significant correlation between individual innovative behavior and team-member exchange (TMX), a similar concept to leader-member exchange that describes high-quality relationships with coworkers. The authors suggested that task interdependence might be a moderator. Unfortunately, this idea has not been examined further. 
Other Team-related Factors. In our review we identified three studies pointing to other team-related factors. Liu et al. (2015) focused on coworkers' $\operatorname{mood}(r=.38$ and .15). Using the affect-as-social-information model (Van Kleef et al., 2010), they found that a coworker's positive mood could increase an employee's voice toward the coworker because it signals that this coworker is likely to accept and welcome suggestions, as reflected in the individual's high psychological safety ("can do"). Choi (2007) focused on the team's vision, or a general transcendent ideal that represents shared values (Kirkpatrick \& Locke, 1996). Perceived team vision affects individual proactive behavior through the individuals' felt responsibility for change ("reason to") and psychological empowerment (“other") because individuals link their own goals and values to the shared ones $(r=.29)$. Similarly, shared team vision was found to affect a team's felt responsibility for change ("reason to") and psychological empowerment (“other”). These two studies again demonstrate that proactive motivation explains why team factors shape individual proactivity. Hoch (2013) focused on team members' dispositional trustworthiness and reliability, captured by team member integrity $(r=.37)$. The author found that high team member integrity, as an ambient input, increased the team's shared leadership, which in turn improved individual innovative behavior.

Last, social network researchers found that employees' network attributes could influence their proactivity. Venkataramani and Tangirala (2010) found that employees with high workflow centrality are likely to perform voice behavior because of the high personal influence in the team $(r=.28)$. Donati, Zappalà, and González-Romá (2016) found that teams with high friendship network density are more likely to actively share feelings, meanings, and ideas with each other, as described by high communication network density. Such highquality communication is helpful for employee innovative behavior. 
Summary of Team-related Factors. Online Supplement Figure 3 provides a summary of these findings. Scholars have mainly focused on the effects of team climate and interactions with coworkers in teams, showing that individuals engage in proactive behavior when there is a positive climate and when interpersonal interactions are favorable. Our review shows mostly positive effects of these social factors, with just a couple of exceptions, including an insignificant correlation between TMX and individual innovative behavior, and somewhat inconsistent evidence regarding the effects of team conflict. There are also reasonably large ranges in correlations, such as the link between proactive behavior-related climates and individual proactive behavior (ranging from $r=-.01$ to $r=.34$ ), which suggests that there are likely to be moderators of some relationships. Overall though, because most team-related factors (e.g., involvement climate, perceived coworker support) have received attention in only a few studies, it is not possible to draw any firm conclusions about the size of these factors' correlation with proactive behavior.

There is clear evidence that proactive motivation variables mediate the effects of team-related factors on proactive behavior, especially "can do" and "reason to" motivational states, with only a few studies finding that "energized to" states serve as mediators. Work engagement, psychological empowerment, thriving, and perceived influence were also found to explain the effects of team-related factors, which further suggests the mediating role of proactive motivations.

Finally, several studies have focused on the role of ambient team-related factors, indicating that ambient social inputs affect both team and individual proactive behavior. Interestingly, Choi (2007) showed that the team-level path to individual proactive behavior is similar to the individual-level one, which is consistent with Chen and Kanfer's (2006) idea that across the team and individual levels, motivational states have similar functions. 
Running Head: Social Context and Proactive Behavior

\section{Organization-Related Factors as Antecedents of Proactive Behavior}

Scholars have mainly focused on top management openness, perceived organization support (POS), organization climate, and workplace relational experiences as organizationrelated predictors for proactive behavior.

Top Management Openness and Perceived Organization Support. Top management openness describes to what degree individuals perceive that top management encourages and welcomes suggestions and comments from below (Morrison \& Phelps, 1999). Its correlation with individual proactive behavior was quite varied, ranging from -.04 (Premeaux \& Bedeian, 2003) to .29 (Morrison \& Phelps, 1999). Ashford, Rothbard, Piderit, and Dutton (1998) found that this factor was positively related to individuals' willingness to promote gender-related issues because it increases individuals' confidence in making change happen, as depicted by the perceived probability of success ("can do"). Adopting a similar logic, Morrison and Phelps (1999) found that top management openness was positively related to taking charge because it indicates a low risk of and high support for initiating changes ("can do").

Perceived organization support (POS) describes the individual perception that the organization values employees' contributions and cares about their well-being (Eisenberger, Armeli, Rexwinkel, Lynch, \& Rhoades, 2001). Its correlation with individual proactive behavior ranged from .03 (Farh, Hackett, \& Liang, 2007) to .15 (Caesens, Marique, Hanin, \& Stinglhamber, 2016). As to how POS might affect proactive behavior, there is some evidence that it shapes "can do" motivation. For example, Ashford et al. (1998) found that POS increased individuals' willingness to sell issues by enhancing the perceived probability of achieving success in such an activity and lowering related image risk. Yuan and Woodman (2010) found that POS affects individuals' innovative behavior through expected image risk and image gain (note that as mentioned above, expected image gain had a negative effect on individual innovative behavior). "Reason to" motivational states are also potential mediators. 
For instance, Caesens et al. (2016) found receiving support from the organization made individuals feel that they had the obligation to reciprocate by performing the proactive behavior. They also found that POS could affect individuals' work engagement, which, as Parker and Griffin (2011) argue, could provide the "energized to" motivation for proactivity.

Two other studies deserve specific attention. First, Burnett, Chiaburu, Shapiro, and Li (2015) found a "too-much-of-a-good-thing” relationship between POS and taking charge. They argued that on one hand, based on social exchange theory (Blau, 1964), POS increases individuals' taking charge by generating a sense of reciprocity and positive affect. On the other hand, according to the threat-to-self-esteem model (Fisher, Nadler, \& Whitcher-Alagna, 1982), when support is overly abundant, individuals are likely to feel that they are not trusted to fulfill their tasks without help. Thus, the relationship should be an inverted U-shape rather than simply linear.

Second, in a study of junior doctors, Parker, Johnson, Collins, and Nguyen (2013) focused on the actual support that individuals received, namely structural support (in the form of an advanced practice nurse on shift), rather than perceptions of support. They argued that the traditional focus on perceived support makes the causal effects of support less clear because individuals who need support might be more likely to seek out or make use of support. ${ }^{8}$ Using a within-person quasi-experiment, they found that compared with a condition without structural support, in the intervention condition with structural support, junior doctors reported significantly more proactive work behavior. Moreover, they found that only doctors with low negative affect had a boost in their proactivity as a result of the intervention. The authors reasoned that this occurred because these individuals have sufficient resources to

\footnotetext{
${ }^{8}$ Caesens et al. (2016) examined whether there is a reciprocal relationship between POS and proactive behavior. They found that Time 1 POS predicts Time 2 proactivity, but Time 2 proactivity could not predict Time 1 POS.
} 
make use of the structural support to enhance their proactive behavior. On the other hand, doctors with high negative affect benefited from structural support in terms of a reduced workload, consistent with the idea that these more stressed doctors are likely to use the support provided to protect future loss rather than being proactive.

Organization Climate. Organization climate describes whether a behavior is encouraged and supported in the organization. It is different from team climate in that it refers to the perception of the broader organizational context. Scholars have mainly focused on individual perceptions of the climate, which reflect their cognitive representations of the organizational environment (Scott \& Bruce, 1994). Its correlation with individual proactive behavior ranged from .00 (Kang, Matusik, Kim, \& Phillips, 2016) to .20 (Eldor \& Harpaz, 2016).

Various proactive behavior-oriented organizational climates have been shown to facilitate proactive behavior, with proactive motivations appearing to be the key mechanisms. For example, Ashford et al. (1998) found that an organization norm that favors issue-selling behavior had a positive effect on people's willingness to sell a gender-equality issue because it reduced the perceived risk that how they are seen by others would be negatively affected ("can do"). Kang et al. (2016) collected a matched sample of managers and their CEOs. They found that managers in a high organizational innovation climate developed a high passion for innovation through identifying with and internalizing the innovation vision. This passion ("energized to") then influenced CEO-rated innovative behavior.

Workplace Interpersonal Interactions. Scholars have also been interested in interpersonal interactions in the workplace, beyond those with teammates and leaders. Favorable workplace interactions were found to have positive effects on individual proactive behavior, mainly through "can do" motivational states. The correlations with individual proactivity ranged from .01 to .57 . For example, Ashford et al. (1998) found that a high 
quality of relationship with whom individuals sell an issue to (usually top management) could increase their perception of the probability of selling success and lower their expected image risk, so that they show a high willingness to sell issues. Ng and Lucianetti (2016) found that individuals' self-efficacy increased because of their trust in the organization and perceived respect from colleagues. With high self-efficacy, they were more likely to engage in the innovative behavior. Vinarski-Peretz, Binyamin, and Carmeli (2011) found that individuals are likely to be affectively committed to their organizations when they have favorable relationship experiences with their colleagues, characterized by positive regard, mutuality, and relational vitality. This commitment ("reason to") encouraged them to perform innovative behaviors.

Wu, Liu, Kwan, and Lee (2016) focused on a negative factor: workplace ostracism ( $r$ $=-.37$ to -.07 ). Based on social identification theory (Ashforth \& Mael, 1989), they argued that when individuals perceive that they are ostracized, they feel that they are different from, unaccepted by, and not valued by others, so that they develop a low level of identification with the organization ("reason to"), which in turn decreases their motivation to be proactive. Of note, they found that this mediation existed even after controlling for other possible mechanisms (felt obligation, OBSE, and job engagement). Perceived organization politics (the perception that the workplace is characterized by the staff's self-serving intentions) was negatively related to individual proactive behavior ( $r=-.24$, Yang, 2017), with "can do" motivation, that is, psychological safety, as the mediator $(r=-.31, \mathrm{Li}, \mathrm{Wu}, \mathrm{Liu}, \mathrm{Kwan}, \& \mathrm{Liu}$, 2014): the greater the perceived politics, the more unsafe individuals felt about being proactive. $\mathrm{Wu}, \mathrm{Kwan}, \mathrm{Wu}$, and $\mathrm{Ma}(2018)$ found that negative gossip in the workplace could serve as a stressor to exhaust employees' resources, manifested as emotional exhaustion, and so reduce their proactive behavior $(r=-.22)$. 
Summary of Organization-related Factors. We summarize the findings in Online

Supplement Figure 4. Research to date shows that individuals are likely to engage in proactive behavior when top management has a positive attitude toward changes, the organization cares about them, the organizational environment encourages proactive behavior, and colleagues interact with them in a positive way. But too much of a good thing can be a bad thing: POS was found to have a curvilinear effect on taking charge (Burnett et al., 2015). As with leader and team factors, there are also negative organizational factors (ostracism and perceived politics) that reduce proactive behavior. With respect to mediation, there is good evidence for "can do," "reason to," and "energized to" motivational states explaining the links between organization-related factors and proactive behavior.

Importantly, overall the correlations between organization-related factors and individual proactive behavior are not very high, perhaps because compared with leader- and team-related factors, these factors are more distal to individual behavior. The large range and low correlations also suggest possible moderation effects, especially of top management openness. Finally, with just one exception (Kang et al., 2016), the studies of organizationrelated factors focus on individual perceptions, so they examine individual-level paths. As a result, although these factors describe organizational characteristics, we do not know how proactive behavior unfolds at the level of the organization as a result of social context factors.

\section{Interaction Effects of Social Context Factors}

Scholars have examined the interaction effects among social context factors and between social context factors and individual attributes (e.g., personality, motivation) as well as job characteristics. These studies support the idea that the social context conditions the relationships among other factors, and that, as mentioned above, there are moderators of the relationship between social context factors and proactive behavior. 
We organize the findings based on the motivational fit perspective (Chen \& Kanfer, 2006). The core idea of this perspective is that "individuals who are predisposed to being motivated (e.g., have higher levels of achievement motivation) are unlikely to be motivated in situations that do not allow them to express their motivational tendencies" (Chen \& Kanfer, 2006, p. 255). That is, motivational inputs from personal and contextual factors should exert stronger influences when they function in a consistent way (Chen et al., 2011). For example, enriched job characteristics have stronger effects on those with a high need for growth (Hackman \& Oldham, 1976), and LMX has a stronger effect on individual psychological empowerment when the ambient empowering leadership is high (Chen, Kirkman, Kanfer, Allen, \& Rosen, 2007). Accordingly, social context factors should have stronger effects on proactive behavior when there is a fit with individual attributes and contextual factors, but weaker effects when there is a misfit with these factors.

\section{Interactions with Individual Attributes}

Taking a person-environment interactionist perspective, Parker et al. (2010) proposed that individual attributes interact with situational factors to affect proactive motivations and proactive behaviors. They specifically drew on trait activation theory (Tett \& Burnett, 2003), which proposes that individual personalities have a stronger effect when there are similar cues in the context. This theory, which has received much support, could be treated as a specific example of the motivational fit perspective. For example, Griffin et al. (2010) found that the perceived leader vision positively interacts with RBSE to affect proactive behavior because only those with high RBSE would accept the challenge of creating changes. Based on the regulatory fit perspective, Wallace et al. (2013) found that an ambient involvement climate positively interacts with an individual promotion focus to affect thriving and thus proactive behavior, because a high promotion focus could enable individuals to better utilize the opportunities created by the climate. Based on the cognitive appraisal theory, Madrid, 
Patterson, Birdi, Leiva, and Kausel (2014) argued that because the goals presented by an innovative climate fits the values, beliefs, and commitments underlying the openness to change personality, individuals with a high openness to experience would appraise this innovative climate more positively. The authors found results consistent with this reasoning.

Consistent with the motivational fit perspective, scholars have also found that when social context factors and individual attributes do not fit each other, they have negative interaction effects. For example, power distance was found to be negatively related to proactive behavior because those with a high power distance perceive a low likelihood that things will change even if they take the initiative (Wei, Zhang, \& Chen, 2015). Farh et al. (2007) and Wei et al. (2015) found that power distance negatively interacts with POS and supervisor delegation to affect individual proactive behavior. In addition, Chen and Aryee (2007) found that in a sample of Chinese employees, traditionality buffers the effect of delegation on individual innovative behavior through OBSE and perceived insider status because highly traditional Chinese employees are likely to accept status differences and act as subordinates when this is their allocated role. Focusing on employees' prosocial motivation, Lebel and Patil (2018) found that it weakened the negative relationships between discouraging leaderships (e.g., distrust in leadership) and proactive behavior.

However, other studies have showed that sometimes elements in either the social context or individual attributes are so strong that one may overpower the influence of the other. For example, Lam and Mayer (2014) found that when the ambient service climate is high, the effect of customer orientation on voice is insignificant because the climate provides strong cues to individuals to do their best to serve customers so that all individuals, despite different levels of customer orientation, would perform voice behavior. Li et al. (2013) found that when team identification, proactive personality, and learning goal orientation are high, the effect of transformational leadership on proactive behavior becomes insignificant. They 
argued that this is because these variables substitute for the functions provided by transformational leadership. These studies thus challenge the motivational fit perspective.

\section{Interaction with Contextual Factors}

The motivational fit perspective has received some support from studies of the interaction among contextual factors that concluded that those with inconsistent motivational effects buffer each other and those with consistent effects enhance each other. For example, Chen et al. (2011) found that team conflict negatively interacted with empowering leadership to influence innovative behavior through psychological empowerment and affective commitment. ${ }^{9}$ Leung, Huang, Su, and Lu (2011) found that when perceived support for innovation is high, the U-shape relationship between role stress and innovative behavior does not exist because the support assists individuals to deal with the negative effect of role stress. Gao, Janssen, and Shi (2011) found that empowering leadership enhances the effect of trust in the leader on voice because empowering leadership invites and encourages individuals to translate their trust into suggestion-making behaviors.

At the same time, there are serious challenges to the motivational perspective, suggesting complexity. That is, some studies have shown that contextual factors that are consistent in their motivational effects buffer each other. For example, Hong et al. (2016) proposed that an initiative-enhanced human resource management system (one that prioritizes employee initiative) would enhance the effect of ambient empowering leadership on the team's initiative climate, which in turn affects individual proactive behavior. This is because (1) such a system attracts, selects, and retains individuals who are ready to be proactive and should be more responsive to an empowering leadership; (2) the consistency between such a system and an empowering leadership could have a synergistic effect on the formation of the initiative climate. However, the results showed a substitution effect. The authors explained

\footnotetext{
${ }^{9}$ This moderated mediation effect was only significant in Study 1.
} 
that the system has already sent strong and clear signals to individuals related to being proactive and thus makes empowering leadership less necessary, which contrasts with the proposition offered by the motivational fit perspective. In addition, Liu et al. (2015) found that coworker exchange and the relative status between the individual and coworker could buffer the effect of the coworker's mood on the individual's psychological safety because a high coworker exchange would reduce the need to monitor the coworker's mood and a relatively high status would lower the motivation to pay attention to social cues. Lam and Mayer (2014) found that when the ambient service climate is high, the effect of job autonomy on individual voice becomes insignificant because the climate has provided strong cues for individuals.

\section{Summary}

Overall, there is certainly good evidence for the motivational fit perspective on how social context factors interact with individual differences and with context factors. But there are also contrary effects, suggesting that there are moderators on the effect of motivational fit. For example, Den Hartog and Belschak (2012) showed a three-way interaction effect among perceived transformational leadership, RBSE, and job autonomy on individual proactive behavior. The authors explained that when job autonomy is low, individuals with high RBSE make use of clear mastery cues to show initiative, making leadership less salient. When job autonomy is high, such cues are absent. As a result, only those with high RBSE could thrive on transformational leaders' high expectations, ambitious vision, and encouragement for extra efforts. In other words, when job autonomy is high, there is a fit effect between transformational leadership and RBSE; but when job autonomy is low, the effect goes in the opposite direction.

Another example is Takeuchi, Chen, and Cheung's (2012) study, which showed a three-way interaction effect among perceived interpersonal justice, procedural justice, and 
distributive justice on individual voice. They argued that perceived interpersonal justice provides interpersonal cues for managing uncertainty about speaking up, and perceived procedure justice provides structure-related cues. According to the elaboration likelihood model (Petty \& Cacioppo, 1986), when perceived distributive justice is high, individuals do not worry about their material outcomes, and thus tend to use either interpersonal or procedural justice as a heuristic to manage uncertainty; but when perceived distributive justice is low, individuals perceive that their material outcomes are at risk, and thus try to scrutinize all possible information. In other words, when perceived distributive justice is high, there is strong challenge to the motivational fit effect; when perceived distributive justice low, the challenge becomes weaker.

\section{Discussion and Future Directions}

We have provided a comprehensive review of a purposive sample of 152 studies focusing on the relationship between social context and proactive behavior. The findings from several different social factors and multiple forms of proactive behavior are synthesized into one model in Online Supplement Figure 5. As our review showed, scholars have mostly focused on leader-related factors as the social antecedents of proactive behavior, with some attention to the effects of team-related factors and relatively little attention to organizationrelated factors. Overall, irrespective of the form of proactive behavior, there is good evidence that leaders' positive behaviors, favorable team and organizational climates, perceived top management openness and support from the organization, and high-quality interaction experiences with teammates and other colleagues increase individual and team proactive behavior. Comparatively fewer studies have examined when the social context becomes an obstacle for proactive behavior, although there is some evidence of the "dark" side of leaderrelated factors (e.g., abusive supervision, undermining behavior, and arrogant attitude), teamrelated factors (e.g., team conflicts) and organizational factors (e.g., workplace ostracism). 
Importantly, proactive motivational states, which we have identified as "can do" (e.g., RBSE), "reason to" (e.g., intrinsic motivation), and "energized to" (e.g., positive affect) motivational states, were found to be key mechanisms explaining why the social context affects proactivity. As for "reason to" motivational states, consistent with the propositions by Parker et al. (2010) and Strauss and Parker (2014), the research has mostly focused on more self-determined forms of motivation, such as intrinsic motivation ( Tu \& Lu, 2013), autonomous motivation (Wu \& Parker, 2017), and identification (Liu et al., 2010). We are somewhat surprised to find that the motivation to reciprocate (e.g., Caesens et al., 2016), which is a less self-determined motivation, was identified as a mediator, a point we return to later. As for "can do" motivational states, self-efficacy perceptions (Wu \& Parker, 2017), perceived risk of being proactive (Yuan \& Woodman, 2010), and perceived probability of success (Ashford et al., 1998) were identified as mediators. Comparably fewer studies have examined "energized to" motivational states as mediators, so we have a more limited understanding of how individuals" "hot" affective motivational states could explain the relationship between social context factors and proactivity.

Scholars have identified some mediators that could not be directly classified into any of these three categories, including psychological empowerment, work engagement, thriving, and judgment of self-worth in the workplace (i.e., OBSE, perceived influence, and perceived status). To explain why these variables operate as mediators, researchers have considered their motivational function. From this perspective, these factors still suggest the mediation roles of proactive motivation. For example, one argument why work engagement influences proactive behavior is that it increases positive affect, an "energized to" state (Schmitt et al., 2006). Similarly, perceived influence was argued to affect proactive behavior because it makes individuals feel that they have a responsibility ("reason to") and capability ("can do") to take initiatives (Tangirala \& Ramanujam, 2012). 
Regarding the effect sizes of the impact of social context factors on proactive behavior, due to the narrative nature of the current review and the fact that some factors, such as perceived organization politics and TMX, have not received much attention, we are not able to come to a clear conclusion about which factor is more important than others. Even so, from our observation of the correlations mentioned above, leader- and team-related factors seem to have slightly stronger effects than organization-related factors, although, in their meta-analysis of voice, Chiaburu et al. (2013) concluded that the effects of positive leader-, team-, and organization-related factors do not differ statistically. Since many studies have emerged their paper, we encourage an expanded meta-analysis to identify whether there are differences in the sizes of social context factors' effects on proactive behavior. Also, because we found that mainly proactive motivations were identified as mediators and Chiaburu et al. called for more attention to the underlying mechanisms in the relationship between the social context and proactive behavior, it would be interesting to meta-analytically examine mediation paths.

Another finding from our observation of the correlations is that the ranges of the effect sizes of social context factors are usually large. For example, the correlation between transformational leadership and individual proactive behavior ranges from .06 to .51 in the identified papers. We think this suggests that there are significant moderators of the relationship between the social context and proactive behavior. Scholars have examined the interaction effects between social context factors and individual attributes as well as contextual factors. The results show inconsistent support for the motivational fit perspective that when two stimuli have consistent motivational patterns, they enhance each other's effect. We will elaborate on this topic shortly.

Finally, scholars have mainly focused on the effects of discretionary factors and have given comparably less attention to ambient factors, as evidenced by the numbers of Paths A, 
Running Head: Social Context and Proactive Behavior

B, and C in Online Supplement Figure 5. Context exists at multiple levels (Bamberger, 2008; Kozlowski \& Klein, 2000; Johns, 2006), so proactivity might develop at different levels of social context in organizations. Thus, the lack of focus on ambient social context factors is problematic, at least from two aspects. First, most discretionary factors are about individual perceptions of the social context. This leads to some confusion about whether it is the way that individuals cognitively perceive their social context or the actual social context itself that affects proactive behavior. Also, as Parker et al. (2013) point out, those who need resources to make changes would actively seek them, thus making the causality of the relationship between the perceptions and proactive behavior unclear. Second, some social aspects of the context are collective, so they cannot be captured by discretionary factors, or at least their meanings change when conceptualized as discretionary factors. For example, team climate, as an ambient factor, reflects team members' shared perception of appropriate behaviors, but perceived climate, as a discretionary factor, only reflects individuals' cognitive representation of the team environment. Thus, ambient social context factors deserve more attention.

The existing studies on ambient social context factors have shown that they influence individual proactive behavior through proactive motivation, similar to discretionary social context factors, as depicted by Path B in Online Supplement Figure 5, although this observation needs more examination. Only a few studies have examined Path $\mathrm{C}$, which pertains to the mediating role of team-level factors. The small number of studies on Path $\mathrm{C} 2$ shows that our understanding of the effect of social context factors on team proactive behavior remains limited. More studies taking a multi-level perspective on the relationship between social context and proactive behavior are needed; otherwise, we may get an overly simplistic and even biased view of how proactive behavior unfolds in the social context.

Our findings contain important practical implications for practitioners. First, they reveal that there are powerful tools to enhance proactive behavior, such as adopting a 
transformational leadership style (Chen et al., 2013), cultivating an innovation climate (Choi, 2007, and improving interpersonal workplace experiences (Vinarski-Peretz et al., 2016).

Second, our findings demonstrate that practitioners could adopt methods that correspond to specific needs. For example, for employees who lack "can do" motivational states, managers could create an initiative-promoting climate (Hong et al., 2016). Third, we emphasize that social interventions are contingent on other factors. Thus, practitioners should take a comprehensive view of individuals' attributes, the social context, job characteristics, and so on to design effective methods to enhance proactive behavior.

Based on our review, we identify twelve key research directions.

\section{Focus More on Factors Beyond Those Related to Leaders}

Team- and organization-related factors have not received as much attention as leaderrelated factors. Yet employees work within an organizational context and often have more frequent interactions with their team members than with their leaders (Chiaburu \& Harrison, 2008). We do not have sufficient understanding of, for example, how organizational cultures (e.g., collectivism vs individualism), coworkers' personalities (e.g., proactive personality), or coworker behaviors (e.g., mentoring, incivility) influence proactive behavior. Further, organizations are embedded in a broader social context, which might impact proactive behavior. For example, in high-tech industries where there is pressure for innovation and initiative and in countries that encourage risk-taking behaivors, employees might engage in a high level of proactive behavior. A largely ignored social subject is the influence of customers, with whom employees might have intense interactions during their work, especially in service industries. Scholars have emphasized that employees should proactively improve their customer services (e.g., Raub \& Liao, 2012), but it would be interesting to look at the flipside: how do customers influence employees' proactive behavior (e.g., Yoo, 2017)? For example, would mistreatment by customers decrease individuals' proactive behavior or 
encourage their voice? In short, we recommend that researchers consider, in greater depth, how social context factors beyond leader-related variables influence proactive behavior.

\section{Focus More on When the Social Context Is an Obstacle for Proactive Behavior}

Existing studies have mainly targeted on how social context fosters proactive behavior in the workplace, giving much less attention to the "dark" side of the social context. Due to negativity bias and the interpersonally risky nature of proactive behavior, individuals might be especially sensitive to de-motivators in the social context. To ignore these factors risks undermining the influence of social context and misleading practitioners into not paying enough attention to the factors that diminish proactive behavior. Moreover, Chen et al. (2011) argue that in reality individuals are exposed to both positive and negative factors simultaneously, so it is important to examine how they compete and interact to influence outcomes. For example, does a Machiavellian leader influence proactive behavior positively or negatively? Does negative leadership buffer the effects of POS or make it more salient? In sum, we recommend further examination of the circumstances in which the social context is an obstacle for proactive behavior.

\section{Clarify the Distinctiveness of Different Social Context Factors}

How are the similar factors different from each other? For example, do transformational and empowering leaderships play different roles in shaping proactive behavior? What about organization innovation climate and team innovation climate? Do trust in the organization and trust in coworkers influence proactive behavior differently? We need more studies that consider several factors at once to ascertain their unique effects. For example, Parker et al. (2006) showed that perceived supportive supervision does not have a significant effect on proactive behavior, but perceived coworker trust does. Ashford et al. (1998) found that POS, issue-selling norms, and relationship quality all influence the perceived risk to one's image of selling issues, but these norms do not affect the perceived 
probability of the successful selling of these issues. In short, we recommend that future studies compare the distinctiveness (e.g., relative effect sizes, unique mechanisms) of different social context factors.

\section{Focus on "Energized to" States and Reconsider the Effect of the Reciprocity Motive}

Overall, "energized to" motivational states have received less attention, which means that we have relatively little idea about whether and how social context factors foster the "hot" affective states that drive proactive behavior. The types of affective states should also be expanded. For example, can the social context affect one's anger, frustration, fear, or enthusiasm, which are theoretically related to proactive behavior (Bindl, Parker, Totterdell, \& Hagger-Johnson, 2012; Lebel, 2016, 2017)?

Somewhat surprisingly, the motivation to reciprocate was shown to be a mediating mechanism between social context and proactive behavior. We think this idea needs more consideration. As the reactive aspect of reciprocity is inconsistent with the self-starting nature of proactive behavior (Spitzmuller \& Van Dyne, 2013), proactive behavior stimulated by social exchange might be unsustainable and have low quality. It is also unclear why individuals choose interpersonally risky proactive behavior rather than safe affiliation behavior for a reciprocal action. For example, Kalshoven et al. (2013) showed that perceived ethical leadership affected personal initiative through a social exchange process, but it is important to assess the longer-term sustainability of the exchange relationship. We recommend further examination of the mediating role of "energized to" motivational states and social exchange motivations in the relationships between social context and proactive behavior.

\section{Examine the Relationship Between Proactive Motivation and "Other" Mediators}

As discussed, scholars have identified other mediators beyond proactive motivations, such as OBSE, psychological empowerment, and work engagement. However, they have 
mainly argued that these variables influence proactive behavior due to their motivational functions. For example, Chen and Aryee (2007) proposed that individuals with high OBSE are motivated to prove their positive self-views. In other words, these individuals see taking risks as consistent with their values and goals ("reason to"). In addition, individuals with high perceived status are motivated to take responsibility for promoting mutual future well-being by showing discretionary efforts ("reason to"). Studies are needed to examine whether these mediators influence proactive behavior through proactive motivation or have additive explanatory effects after controlling for proactive motivation. We recommend that future studies investigate the relationships between proactive motivations and other mediators identified in this review.

\section{Examine the Mediation Effects of Cognition and Capacity Factors}

Proactive behavior entails cognitively projecting oneself into future events and assessing possible outcomes (Wu, Parker, \& de Jong, 2014). Accordingly, one's cognitionrelated factors might serve as mechanisms linking social factors with proactive behavior. For example, since proactive behavior entails envisioning a different future and transformational leadership inspires individuals to strive for a desirable vision, high work-based construal level might be a mediator between these two variables. In addition, individuals do not only need to generate proactive goals to bring about changes; they also need the relevant capacities to strive for these goals (Parker et al., 2010). In this sense, the various capabilities involved in proactive behavior might also explain why social context affects proactive behavior. For example, Parker and $\mathrm{Wu}$ (2014) proposed that the capacities of long-term thinking and integrated understanding could mediate leaders' effects on individual proactive behavior. We recommend that future studies explore the mediation effects of cognition and capacity factors to reveal the non-motivational effects of proactive behavior. 


\section{Examine the Too-Much-of-a-Good(Bad)-Thing Effect}

Burnett et al. (2015) found that POS has a curvilinear effect on taking charge because of two competing mechanisms: social exchange and threat to self-esteem. We encourage scholars to pay more attention to the potentially negative mechanisms operating against positive mechanisms related to social context factors. For example, Den Hartog and Belschak (2017) argued that transformational leadership might stifle proactive behavior, for example, by building too much dependence. Similarly, negative social context factors might not always be detrimental; for example, perceived abusive supervision might motivate individuals to prove that the leader is wrong (Tepper et al., 2017). Indeed, researchers have argued that to be proactive, a certain level of dissatisfaction with the status quo is needed. In this sense, could there be an optimal level of negative social experiences? For example, could perceived abusive supervision have a curvilinear effect on individual proactive behavior? We encourage scholars to examine whether social context factors have influences in opposite directions so that there are too-much-of-a-good(bad)-thing effects.

\section{Examine the Distinct Explanatory and Interaction Effects of Different Mediators}

The large number of mediators is helpful to gain new insights into why social context matters to proactive behavior, but at the same time brings the problem that we are not clear about the relative explanatory power of each mediator. For example, Strauss and Parker (2014) propose that intrinsic and extrinsic forms of "reason to" states have different effects on proactive behavior. The relative role of "reason to" and "can do" motivation is also interesting. On the one hand, Parker et al. (2010) argued that based on construal-level theory (Liberman \& Trope, 1998), for distant proactive goals, "reason to" should be more important than "can do." On the other hand, Chen et al. (2013), Hong et al. (2016), and Walumbwa and Hartnell (2011) consistently found that when examining the effects of "can do" and "reason to" motivational states simultaneously, only "can do" states are the significant mediator. This 
implies that social context influences individual proactive behavior more through the "can do" paradigm, which is consistent with the interpersonally risky nature of proactive behavior. We encourage scholars to replicate the findings, with different social context factors at different levels as predictors. Moreover, according to the proactive motivation model (Parker et al. 2010), different motivational states might interactively influence proactive behavior. In this sense, it would be interesting to examine whether these different mechanisms could exaggerate or attenuate each other's effects. For example, since transformational leadership was found to influence proactive behavior through both "reason to" and "can do" motivational states, could both mechanisms exaggerate each other's effect? We recommend that research investigates the distinct explanatory and possible interactive effects of different mediators.

\section{Further Examine the Interaction Effects of Social Context Factors}

Existing studies have produced contrasting evidence for the motivational-fit perspective that social context factors enhance the effects of other factors that have consistent motivating functions and decrease the effects of other factors that have inconsistent motivating functions. One explanation for this is that there are other factors that could determine the need for either or both motivators. In this case, researchers could rely on theories that describe individuals' needs to pay attention to the social context to examine under which circumstances the motivational-fit effect would occur. For example, social information processing theory (Salancik \& Pfeffer, 1978) proposes that high situational uncertainty increases individuals' need for social information, resulting in the prediction that when uncertainty is high, the motivational-fit effect would happen.

Another possible explanation is that motivational fit depends on the functions of the variables. For example, $\mathrm{Wu}$ and $\mathrm{Li}$ (2017) differentiated proactivity-related personality traits into cognitive (e.g., need for cognition), affective (e.g., trait positive affect), instrumental 
(e.g., proactive personality), and interpersonal (e.g., attachment styles) ones. The social context factors providing different functions might enhance these traits' effect (e.g., initiative climate and need for cognition) and those with schematically related cues might activate corresponding traits (e.g., leader support and attachment styles, Wu \& Parker, 2017). But a social context with similar functions to the traits might buffer the effect of these traits (e.g., transformational leadership and proactive personality, Li et al., 2013).

We acknowledge that these are preliminary explanations of when motivation-fit effects happen and when they do not. Our main aim is to encourage research into further examination of the interaction effects of social context factors.

\section{Focus More on Ambient Social Context Factors}

Discretionary factors mainly describe individuals' own experiences and how individuals perceive the social context, but ambient factors capture the collective properties in the social context. Given the relatively lower understanding of ambient factors, we encourage more relevant studies. Specifically, we encourage scholars to examine whether the relationship between the social context and proactive behavior is homologous across the levels of the team and, where possible, the organization (Chen \& Kanfer, 2006). Such studies will help us gain insight into how social context affects proactive team behavior, a neglected topic. As Harris and Kirkman (2017) observe, to deal with high uncertainty in workplaces (Griffin et al., 2007), teams need to be effective. Since proactive behavior reflects personenvironment interactions, the social context should have a significant effect on proactive team behavior. We have little insight as to whether, how, and under which circumstances social context affects proactive team behavior.

To elaborate, researchers could examine whether Paths $\mathrm{C}$ and $\mathrm{A}$ in Figure 5 are similar. Chen and Kanfer (2006) propose that motivational states function similarly at the team and individual levels; thus we could expect that ambient social context factors influence 
proactive individual and team behavior through similar mediators to discretionary ones. But at the same time, as Mathieu et al. (2008) state, at the team level there are some variables describing the processes and emergent states that do not exist at the individual level, such as the team potency. In this case, ambient social context factors might have unique influences on proactive behavior through these team processes and states.

To conduct such examinations, researchers should include multiple paths. For example, Tu and Lu (2013) investigated the effects of perceived individual and team ethical leadership on individual innovative behavior through individual and team intrinsic motivations (Paths A, B, and C1) and showed homologous effects at different levels. In the future, scholars should keep asking, for example, what is the difference between perceived and ambient transformational leadership? Are the effects of perceived climate and team climate similar? What are the unique team-level mediators? We recommend more focus on ambient social context factors.

\section{Examine Bottom-up Effects of Social Context on Proactivity}

As Bamberger (2008) suggested, it would be interesting to explore and explain the bottom-up processes, such as how discretionary social context factors affect team and organizational proactivity. Specifically, Chen and Kanfer (2006) have proposed Path G, through which the motivational states of the team and the individual might influence each other, and Path $\mathrm{H}$, wherein proactive individual behavior might influence team behavior. For example, individuals who are confident in their abilities (self-efficacy, "can do") will perform their roles well and also be confident in their teams' capability (team efficacy, “can do"). In other words, "can do"-related discretionary factors might shape team proactivity via team efficacy (Path G). Also, Chen and Kanfer (2006) describe a social-learning process (e.g., behavior modeling, social contagion) through which individual behavior contributes to collective actions (Chen et al., 2013), suggesting that discretionary factors could shape team 
proactivity through individual proactivity (Path $\mathrm{H})$. However, no studies have examined these two paths. We think this might be because of the lack of a relevant theoretical framework; thus we hope that we could encourage future studies to examine the bottom-up effect of discretionary social context factors on team and organizational proactivity.

\section{Examine Organization-level Paths}

Organizations might have unique influences on proactive behavior through their systems and structures. But this is largely unknown to us at this stage. As an important factor for organizational success (Crant, 2000), proactive behavior at the organizational level is worth more attention. For example, Weiss, Kolbe, Grote, Spahn, and Grande (2017) found that after-event-review-based intervention could improve team member voice. Thus, it is likely that when organizations adopt specific interventions (such as redesign their systems), they could improve individual, team, and even organization proactivity by changing interpersonal stimuli in the organization.

Moreover, examining organization-level paths gives us the opportunity to gain new ways of seeing the effects of social context. For example, in the industrial relations literature, Arthur and Aiman-Smith (2001) found that introducing a gainsharing plan could increase the number of suggestions that promote organizational learning. This implies that by changing the relationship between employees and the organization - obviously a social context factor, the gainsharing plan could increase organization voice. In the international business literature, Newman and Nollen (1996) found that the congruence between management practices and the national culture would influence organizational performance. In this case, we expect that the national culture, as a country-level social context factor, could have an indirect effect on organizational proactive behavior. We recommend extending the scope of research to the organization-level path. 
Running Head: Social Context and Proactive Behavior

\section{Conclusion}

From an interactionist perspective, social context plays a critical role in shaping proactive behavior in workplace. Our comprehensive review aims to close the gaps in a disparate literature studying multiple social context factors and multiple proactive behaviors. We recommend further investigating the relationship between social context and proactive behavior, such as through using the integrative model depicted in Online Supplement Figure 5. Most importantly, we hope that this review could serve to create a favorable academic social context that encourages researchers to perform research-related proactive behavior to address these opportunities! 


\section{Key References ${ }^{10}$}

Bamberger, P. (2008). From the Editors Beyond Contextualization: Using Context Theories to Narrow the Micro-Macro Gap in Management Research. Academy of Management Journal, 51, 839-846. https://doi.org/10.5465/amj.2008.34789630

Bindl, U. K., \& Parker, S. K. (2017). New Perspectives and Directions for Understanding Proactivity in Organizations. In S. K. Parker, \& U. K. Bindl (Eds.), Proactivity at Work (pp. 559 - 584). Oxford, OX: Routledge.

Cappelli, P., \& Sherer, P. D. (1991). The missing role of context in OB: The need for a mesolevel approach. Research in Organizational Behavior, 13, 55-110. https://doi.org/10.1017/CBO9781107415324.004

Chen, G., Farh, J. L., Campbell-Bush, E. M., Wu, Z., \& Wu, X. (2013). Teams as innovative systems: Multilevel motivational antecedents of innovation in R\&D teams. Journal of Applied Psychology, 98, 1018-1027. https://doi.org/10.1037/a0032663

Chen, G., \& Kanfer, R. (2006). Toward a Systems Theory of Motivated Behavior in Work Teams. Research in Organizational Behavior, 27, 223-267. https://doi.org/10.1016/S0191-3085(06)27006-0

Chen, G., Sharma, P. N., Edinger, S. K., Shapiro, D. L., \& Farh, J. L. (2011). Motivating and Demotivating Forces in Teams: Cross-Level Influences of Empowering Leadership and Relationship Conflict. Journal of Applied Psychology, 96, 541-557. https://doi.org/10.1037/a0021886

Choi, J. N. (2007). Change-oriented organizational citizenship behavior: Effects of work environment characteristics and intervening psychological processes. Journal of Organizational Behavior, 28, 467-484. https://doi.org/10.1002/job.433

${ }^{10}$ For other references, please see Online Supplement References. 
Running Head: Social Context and Proactive Behavior

Harris, T. B., \& Kirkman, B. (2017). Teams and proactivity. In S. K. Parker, \& U. K. Bindl (Eds.), Proactivity at Work (pp. 530-558). Oxford, OX: Routledge.

Hong, Y., Liao, H., Raub, S., \& Han, J. H. (2016). What it takes to get proactive: An integrative multilevel model of the antecedents of personal initiative. Journal of Applied Psychology, 101, 687-701. https://doi.org/10.1037/ap10000064

Johns, G. (2006). The essential impact of content on organizational behavior. Academy of Management Review, 31, 386-408. https://doi.org/10.5465/AMR.2006.20208687

Johns, G. (2018). Advances in the Treatment of Context in Organizational Research. Annual Review of Organizational Psychology and Organizational Behavior, 5, 21-46. https://doi.org/10.1146/annurev-orgpsych-032117-104406

Mowday, R. T., \& Sutton, R. I. (1993). Organizational behaviour: Linking individuals and groups to organizational context. Annual Review of Psychology, 44, 195-229. https://doi.org/10.1146/annurev.ps.44.020193.001211

Parker, S. K., Bindl, U. K., \& Strauss, K. (2010). Making things happen: A model of proactive motivation. Journal of Management, 36, 827-856. https://doi.org/10.1177/0149206310363732

Parker, S. K., \& Collins, C. G. (2010). Taking stock: Integrating and differentiating multiple proactive behaviors. Journal of Management, 36, 633-662. https://doi.org/10.1177/0149206308321554

Parker, S. K., Williams, H. M., \& Turner, N. (2006). Modeling the antecedents of proactive behavior at work. Journal of Applied Psychology, 91, 636-652. https://doi.org/10.1037/0021-9010.91.3.636

Strauss, K., \& Parker, S.K. (2014). Effective and sustained proactivity in the workplace: A self-determination theory perspective. In M. Gagné (Ed.), The Oxford Handbook of 
Work Engagement, Motivation, and Self-Determination Theory (pp. 50-71). Oxford, OX: Oxford University Press.

Tu. L., \& Lu. X. (2013). How Ethical Leadership Influence Employees' Innovative Work Behavior: A Perspective of Intrinsic Motivation. Journal of Business Ethics, 116, 441455. https://doi.org/10.1007/s10551-012-1455-7

Williams, H. M., Parker, S. K., \& Turner, N. (2010). Proactively performing teams: The role of work design, transformational leadership, and team composition. Journal of Occupational and Organizational Psychology, 83, 301-324. https://doi.org/10.1348/096317910X502494 


\section{Online Supplement References}

Arthur, J. B., \& Aiman-Smith, L. (2001). Gainsharing and organizational learning: An analysis of employee suggestions over time. Academy of Management Journal, 44, 737-754. https://doi.org/10.5465/3069413

Ashford, S. J., Rothbard, N. P., Piderit, S. K., \& Dutton, J. E. (1998). Out on a Limb: The Role of Context and Impression Management in Selling Gender-Equity Issues. Administrative Science Quarterly, 43, 23-57. https://doi.org/10.2307/2393590

Ashforth, B. E., \& Mael, F. (1989). Social identity theory and the organization. Academy of Management Review, 14, 20-39. https://doi.org/10.2307/258189

Axtell, C. M., Holman, D. J., Unsworth, K. L., Wall, T. D., Waterson, P. E., \& Harrington, E. (2000). Shopfloor innovation: Facilitating the suggestion and implementation of ideas. Journal of Occupational and Organizational Psychology, 73, 265-285. https://doi.org/10.1348/096317900167029

Baer, M., \& Frese, M. (2002). Innovatuion is not enough: Climates for initiative and psychological safety. Contemporary Accounting Research, 50, 83-101. https://doi.org/10.1002/job.179

Belschak, F. D., \& Den Hartog, D. N. D. (2010). Pro-self, prosocial, and pro-organizational foci of proactive behaviour: Differential antecedents and consequences. Journal of Occupational and Organizational Psychology, 83, 475-498. https://doi.org/10.1348/096317909X439208

Bienefeld, N., \& Grote, G. (2014). Speaking up in ad hoc multiteam systems: Individual-level effects of psychological safety, status, and leadership within and across teams. European Journal of Work and Organizational Psychology, 23, 930-945. https://doi.org/10.1080/1359432X.2013.808398

Bindl, U. K., Parker, S. K., Totterdell, P., \& Hagger-Johnson, G. (2012). Fuel of the self- 
starter: How mood relates to proactive goal regulation. Journal of Applied Psychology, 97, 134-150. https://doi.org/10.1037/a0024368

Blau, P. 1964. Exchange and power in social life. New York, NY: Wiley.

Borden, L., Levy, P. E., \& Silverman, S. B. (2018). Leader Arrogance and Subordinate Outcomes: the Role of Feedback Processes. Journal of Business and Psychology, 33, 345-364. https://doi.org/10.1007/s10869-017-9501-1

Brav, A., Andersson, K., \& Lantz, A. (2009). Group initiative and self-organizational activities in industrial work groups. European Journal of Work and Organizational Psychology, 18, 347-377. https://doi.org/10.1080/13594320801960482

Brown, M. E., Treviño, L. K., \& Harrison, D. A. (2005). Ethical leadership: A social learning perspective for construct development and testing. Organizational Behavior and Human Decision Processes, 97, 117-134.

https://doi.org/10.1016/J.OBHDP.2005.03.002

Burnett, M. F., Chiaburu, D. S., Shapiro, D. L., \& Li, N. (2015). Revisiting How and When Perceived Organizational Support Enhances Taking Charge: An Inverted U-Shaped Perspective. Journal of Management, 41, 1805-1826.

https://doi.org/10.1177/0149206313493324

Burris, E. R., Detert, J. R., \& Chiaburu, D. S. (2008). Quitting Before Leaving: The Mediating Effects of Psychological Attachment and Detachment on Voice. Journal of Applied Psychology, 93, 912-922. https://doi.org/10.1037/0021-9010.93.4.912

Caesens, G., Marique, G., Hanin, D., \& Stinglhamber, F. (2016). The relationship between perceived organizational support and proactive behaviour directed towards the organization. European Journal of Work and Organizational Psychology, 25, 398411. https://doi.org/10.1080/1359432X.2015.1092960

Chen, A. S. Y., \& Hou, Y. H. (2016). The effects of ethical leadership, voice behavior and 
climates for innovation on creativity: A moderated mediation examination. Leadership Quarterly, 27, 1-13. https://doi.org/10.1016/j.leaqua.2015.10.007

Chen, G., \& Bliese, P. D. (2002). The role of different levels of leadership in predicting selfand collective efficacy: Evidence for discontinuity. Journal of Applied Psychology, 87, 549-556. https://doi.org/10.1037//0021-9010.87.3.549

Chen, G., Kirkman, B. L., Kanfer, R., Allen, D., \& Rosen, B. (2007). A multilevel study of leadership, empowerment, and performance in teams. Journal of Applied Psychology, 92, 331-346. https://doi.org/10.1037/0021-9010.92.2.331

Chen, T., Li, F., \& Leung, K. (2016). When Does Supervisor Support Encourage Innovative Behavior? Opposite Moderating Effects of General Self-efficacy and Internal Locus of Control. Personnel Psychology, 69, 123-158. https://doi.org/10.1111/peps.12104

Chen, X. P., He, W., \& Weng, L. C. (2018). What Is Wrong With Treating Followers Differently? The Basis of Leader-Member Exchange Differentiation Matters. Journal of Management, 44, 946-971. https://doi.org/10.1177/0149206315598372

Chen, Z. X., \& Aryee, S. (2007). Delegation And Employee Work Outcomes: An Examination Of The Cultural Context Of Mediating Processes In China. Academy of Management Journal, 50, 226-238. https://doi.org/10.5465/amj.2007.24162389

Chiaburu, D. S., \& Harrison, D. A. (2008). Do Peers Make the Place? Conceptual Synthesis and Meta-Analysis of Coworker Effects on Perceptions, Attitudes, OCBs, and Performance. Journal of Applied Psychology, 93, 1082-1103. https://doi.org/10.1037/0021-9010.93.5.1082

Chiaburu, D. S., Lorinkova, N. M., \& Van Dyne, L. (2013). Employees' Social Context and Change-Oriented Citizenship: A Meta-Analysis of Leader, Coworker, and Organizational Influences. Group and Organization Management, 38, 291-333. https://doi.org/10.1177/1059601113476736 
Crant, J. M. (2000). Proactive behavior in organizations. Journal of Management, 26, 435462. https://doi.org/10.1016/S0149-2063(00)00044-1

Crant, J. M., Hu, J., \& Jiang, K. (2017). Proactive Personality. In S. K. Parker, \& U. K. Bindl (Eds.), Proactivity at Work (pp. 193-225). Oxford, OX: Routledge.

Den Hartog, D. N., \& Belschak, F. D. (2012). When does transformational leadership enhance employee proactive behavior? The role of autonomy and role breadth selfefficacy. Journal of Applied Psychology, 97, 194-202. https://doi.org/10.1037/a0024903

Den Hartog, D. N., \& Belschak, F. D. (2017). Leadership and employee proactivity. In S. K. Parker, \& U. K. Bindl (Eds.), Proactivity at Work (pp. 434-468). Oxford, OX: Routledge.

Detert, J. R., \& Burris, E. R. (2007). Leadership Behavior and Employee Voice: Is the Door Really Open? Academy of Management Journal, 50, 869-884. https://doi.org/10.5465/amj.2007.26279183

Donati, S., Zappalà, S., \& González-Romá, V. (2016). The influence of friendship and communication network density on individual innovative behaviours: a multilevel study. European Journal of Work and Organizational Psychology, 25, 583-596. https://doi.org/10.1080/1359432X.2016.1179285

Duan, J., Li, C., Xu, Y., \& Wu, C. (2017). Transformational leadership and employee voice behavior: A Pygmalion mechanism. Journal of Organizational Behavior, 38, 650670. https://doi.org/10.1002/job.2157

Eisenberger, R., Armeli, S., Rexwinkel, B., Lynch, P. D., \& Rhoades, L. (2001). Reciprocation of perceived organizational support. Journal of Applied Psychology, 86, 42-51. https://doi.org/10.1037//0021-9010.86.1.42

Eldor, L., \& Harpaz, I. (2016). A process model of employee engagement: The learning 
climate and its relationship with extra-role performance behaviors. Journal of Organizational Behavior, 37, 213-235. https://doi.org/10.1002/job.2037

Farh, C. I. C., \& Chen, Z. (2014). Beyond the individual victim: Multilevel consequences of abusive supervision in teams. Journal of Applied Psychology, 99, 1074-1095. https://doi.org/10.1037/a0037636

Farh, J. L., Hackett, R. D., \& Liang, J. (2007). Individual-level cultural values as moderators of perceived organizational support-employee outcomes relationships: Comparing the effects of power distance and traditionality. Academy of Management Journal, 50, 715-729. https://doi.org/10.5465/amj.2007.25530866

Farrell, J. B., \& Strauss, K. (2013). The people make the place, and they make things happen: Proactive Behavior and relationships at work. In Cooper-Thomas, H. \& Morrison, R. (Eds.), Relationships in organisations: A work psychology perspective (pp. 107 136). London: Palgrave Macmillan.

Fast, N. J., Burris, E. R., \& Bartel, C. A. (2014). Managing to stay in the dark: Managerial self-efficacy, ego defensiveness, and the aversion to employee voice. Academy of Management Journal, 57, 1013-1034. https://doi.org/10.5465/amj.2012.0393

Fisher, J. D., Nadler, A., \& Whitcher-Alagna, S. (1982). Recipient reactions to aid. Psychological Bulletin, 91, 27-54. https://doi.org/10.1037//0033-2909.91.1.27

Frazier, M. L., \& Bowler, W. M. (2015). Voice Climate, Supervisor Undermining, and Work Outcomes: A Group-Level Examination. Journal of Management, 41, 841-863. https://doi.org/10.1177/0149206311434533

Fredrickson, B. L. (2001). The role of positive emotions in positive psychology: The broaden-and-build theory of positive emotions. American Psychologist, 56, 218-226. https://doi.org/10.1037/0003-066X.56.3.218

Gao, L., Janssen, O., \& Shi, K. (2011). Leader trust and employee voice: The moderating role 
of empowering leader behaviors. Leadership Quarterly, 22, 787-798. https://doi.org/10.1016/j.leaqua.2011.05.015

Griffin, M. A., Parker, S. K., \& Mason, C. M. (2010). Leader Vision and the Development of Adaptive and Proactive Performance: A Longitudinal Study. Journal of Applied Psychology, 95, 174-182. https://doi.org/10.1037/a0017263

Hackman, J. R., \& Oldham, G. R. (1976). Motivation through the design of work: test of a theory. Organizational Behavior and Human Performance, 16, 250-279. https://doi.org/10.1016/0030-5073(76)90016-7

He, W., Zhou, R.-Y., Long, L.-R., Huang, X., \& Hao, P. (2018). Self-Sacrificial Leadership and Followers' Affiliative and Challenging Citizenship Behaviors: A Relational SelfConcept Based Study in China. Management and Organization Review, 14, 105-133. https://doi.org/10.1017/mor.2017.9

Hobfoll, S. E. (1989). Conservation of resources: A new attempt at conceptualizing stress. American Psychologist, 44, 513-524. https://doi.org/10.1037//0003-066X.44.3.513

Hoch, J. E. (2013). Shared Leadership and Innovation: The Role of Vertical Leadership and Employee Integrity. Journal of Business and Psychology, 28, 159-174. https://doi.org/10.1007/s10869-012-9273-6

Janssen, O., \& Gao, L. (2015). Supervisory Responsiveness and Employee Self-Perceived Status and Voice Behavior. Journal of Management, 41, 1854-1872. https://doi.org/10.1177/0149206312471386

Kalshoven, K., Den Hartog, D. N., \& de Hoogh, A. H. B. (2013). Ethical leadership and followers' helping and initiative: The role of demonstrated responsibility and job autonomy. European Journal of Work and Organizational Psychology, 22, 165-181. https://doi.org/10.1080/1359432X.2011.640773

Kang, J. H., Matusik, J. G., Kim, T. Y., \& Phillips, J. M. (2016). Interactive effects of 
multiple organizational climates on employee innovative behavior in entrepreneurial firms: A cross-level investigation. Journal of Business Venturing, 31, 628-642. https://doi.org/10.1016/j.jbusvent.2016.08.002

Kirkman, B. L., \& Rosen, B. (1999). Beyond Self-Management: Antecedents and Consequences of Team Empowerment. Academy of Management Journal, 42, 58-74. https://doi.org/10.5465/256874

Kirkpatrick, S. A., \& Locke, E. A. (1996). Direct and indirect effects of three core charismatic leadership components on performance and attitudes. Journal of Applied psychology, 81, 36-51. https://doi.org/10.1037//0021-9010.81.1.36

Kuonath, A., Specht, J., Kühnel, J., Pachler, D., \& Frey, D. (2017). Keeping up day-specific effects of transformational leadership: the role of followers' emotion regulation. European Journal of Work and Organizational Psychology, 26, 828-843. https://doi.org/10.1080/1359432X.2017.1379993

Lam, C. F., \& Mayer, D. M. (2014). When do employees speak up for their customers? A model of voice in a customer service context. Personnel Psychology, 67, 637-666. https://doi.org/10.1111/peps. 12050

Lebel, R. D. (2016). Overcoming the fear factor: How perceptions of supervisor openness lead employees to speak up when fearing external threat. Organizational Behavior and Human Decision Processes, 135, 10-21. https://doi.org/10.1016/j.obhdp.2016.05.001

Lebel, R. D. (2017). Moving Beyond Fight and Flight: A Contingent Model of How the Emotional Regulation of Anger and Fear Sparks Proactivity. Academy of Management Review, 42, 190-206. https://doi.org/10.5465/amr.2014.0368

Lebel, R. D., \& Patil, S. V. (2018). Proactivity despite discouraging supervisors: The powerful role of prosocial motivation. Journal of Applied Psychology, 103, 724-737. 
https://doi.org/10.1037/ap10000301

Lee, A., Willis, S., \& Tian, A. W. (2018). Empowering leadership: A meta-analytic examination of incremental contribution, mediation, and moderation. Journal of Organizational Behavior, 39, 306-325. https://doi.org/10.1002/job.2220

Lee, K., Duffy, M. K., Scott, K. L., \& Schippers, M. C. (2018). The experience of being envied at work: How being envied shapes employee feelings and motivation. Personnel Psychology, 71, 181-200. https://doi.org/10.1111/peps.12251

Leung, K., Huang, K.-L., Su, C.-H., \& Lu, L. (2011). Curvilinear relationships between role stress and innovative performance: Moderating effects of perceived support for innovation. Journal of Occupational and Organizational Psychology, 84, 741-758. https://doi.org/10.1348/096317910X520421

Li, J., Wu, L. Z., Liu, D., Kwan, H. K., \& Liu, J. (2014). Insiders maintain voice: A psychological safety model of organizational politics. Asia Pacific Journal of Management, 31, 853-874. https://doi.org/10.1007/s10490-013-9371-7

Li, N., Chiaburu, D. S., Kirkman, B. L., \& Xie, Z. (2013). Spotlight on the Followers: An Examination of Moderators of Relationships Between Transformational Leadership and Subordinates' Citizenship and Taking Charge. Personnel Psychology, 66, 225260. https://doi.org/10.1111/peps.12014

Li, S. L., He, W., Yam, K. C., \& Long, L. R. (2015). When and why empowering leadership increases followers' taking charge: A multilevel examination in China. Asia Pacific Journal of Management, 32, 645-670. https://doi.org/10.1007/s10490-015-9424-1

Liang, S. G. (2017). Linking leader authentic personality to employee voice behaviour: a multilevel mediation model of authentic leadership development. European Journal of Work and Organizational Psychology, 26, 434-443. https://doi.org/10.1080/1359432X.2017.1293656 
Liao, E. Y., \& Chun, H. (2016). Supervisor monitoring and subordinate innovation. Journal of Organizational Behavior, 37, 168-192. https://doi.org/10.1002/job.2035

Liberman, N., \& Trope, Y. (1998). The role of feasibility and desirability considerations in near and distant future decisions: A test of temporal construal theory. Journal of Personality and Social Psychology, 75, 5-18. https://doi.org/10.1037//00223514.75.1.5

Lin, C. C., Kao, Y. T., Chen, Y. L., \& Lu, S. C. (2016). Fostering Change-Oriented Behaviors: A Broaden-and-Build Model. Journal of Business and Psychology, 31, 399-414. https://doi.org/10.1007/s10869-015-9417-6

Lin, X., \& Leung, K. (2014). What signals does procedural justice climate convey? The roles of group status, and organizational benevolence and integrity. Journal of Organizational Behavior, 35, 464-488. https://doi.org/10.1002/job.1899

Liu, H., Ting-Ju Chiang, J., Fehr, R., Xu, M., \& Wang, S. (2017). How do leaders react when treated unfairly? Leader narcissism and self-interested behavior in response to unfair treatment. Journal of Applied Psychology, 102, 1590-1599. https://doi.org/10.1037/ap10000237

Liu, W., Tangirala, S., Lam, W., Chen, Z., Jia, R. T., \& Huang, X. (2015). How and when peers' positive mood influences employees' voice. Journal of Applied Psychology, 100, 976-989. https://doi.org/10.1037/a0038066

Liu, W., Tangirala, S., \& Ramanujam, R. (2013). The relational antecedents of voice targeted at different leaders. Journal of Applied Psychology, 98, 841-851. https://doi.org/10.1037/a0032913

Liu, W., Zhu, R., \& Yang, Y. (2010). I warn you because I like you: Voice behavior, employee identifications, and transformational leadership. Leadership Quarterly, 21, 189-202. https://doi.org/10.1016/j.leaqua.2009.10.014 
López-Domínguez, M., Enache, M., Sallan, J. M., \& Simo, P. (2013). Transformational leadership as an antecedent of change-oriented organizational citizenship behavior. Journal of Business Research, 66, 2147-2152. https://doi.org/10.1016/j.jbusres.2013.02.041

Lord, R. G., Gatti, P., \& Chui, S. L. M. (2016). Social-cognitive, relational, and identitybased approaches to leadership. Organizational Behavior and Human Decision Processes, 136, 119-134. https://doi.org/10.1016/j.obhdp.2016.03.001

Madrid, H. P., Patterson, M. G., Birdi, K. S., Leiva, P. I., \& Kausel, E. E. (2014). The role of weekly high-activated positive mood, context, and personality in innovative work behavior: A multilevel and interactional model. Journal of Organizational Behavior, 35, 234-256. https://doi.org/10.1002/job.1867

Marinova, S. V., Peng, C., Lorinkova, N., Van Dyne, L., \& Chiaburu, D. (2015). Changeoriented behavior: A meta-analysis of individual and job design predictors. Journal of Vocational Behavior, 88, 104-120. https://doi.org/10.1016/j.jvb.2015.02.006

Martin, S. L., Liao, H., \& Campbell, E. M. (2013). Directive versus Empowering Leadership: A Field Experiment Comparing Impacts on Task Proficiency and Proactivity. Academy of Management Journal, 56, 1372-1395. https://doi.org/10.5465/amj.2011.0113

Mathieu, J., Maynard, T. M., Rapp, T., \& Gilson, L. (2008). Team effectiveness 1997-2007: A review of recent advancements and a glimpse into the future. Journal of Management, 34, 410-476. https://doi.org/10.1177/0149206308316061

McAllister, D. J., Kamdar, D., Morrison, E. W., \& Turban, D. B. (2007). Disentangling Role Perceptions: How Perceived Role Breadth, Discretion, Instrumentality, and Efficacy Relate to Helping and Taking Charge. Journal of Applied Psychology, 92, 1200-1211. https://doi.org/10.1037/0021-9010.92.5.1200 
Montani, F., Odoardi, C., \& Battistelli, A. (2014). Individual and contextual determinants of innovative work behaviour: Proactive goal generation matters. Journal of Occupational and Organizational Psychology, 87, 645-670. https://doi.org/10.1111/joop.12066

Morrison, E. W., \& Phelps, C. C. (1999). Taking charge at work: Extrarole effort. Academy of Management Journal, 42, 403-419. https://doi.org/10.2307/257011

Morrison, E. W., Wheeler-Smith, S. L., \& Kamdar, D. (2011). Speaking Up in Groups: A Cross-Level Study of Group Voice Climate and Voice. Journal of Applied Psychology, 96, 183-191. https://doi.org/10.1037/a0020744

Newman, K. L., \& Nollen, S. D. (1996). Culture and congruence: The fit between management practices and national culture. Journal of International Business Studies, 27, 753-779. https://doi.org/10.1057/palgrave.jibs.8490152

Ng, T. W. H., \& Feldman, D. C. (2012). Employee voice behavior: A meta-analytic test of the conservation of resources framework. Journal of Organizational Behavior, 33, 216-234. https://doi.org/10.1002/job.754

Ng, T. W. H., \& Feldman, D. C. (2013). Changes in Perceived Supervisor Embeddedness: Effects on Employees’ Embeddedness, Organizational Trust, and Voice Behavior. Personnel Psychology, 66, 645-685. https://doi.org/10.1111/peps.12025

Niessen, C., Mäder, I., Stride, C., \& Jimmieson, N. L. (2017). Thriving when exhausted: The role of perceived transformational leadership. Journal of Vocational Behavior, 103, 41-51. https://doi.org/10.1016/j.jvb.2017.07.012

Nifadkar, S., Tsui, A. S., \& Ashforth, B. E. (2012). The Way You Make Me Feel and Behave: Supervisor-Triggered Newcomer Affect and Approach-Avoidance Behavior. Academy of Management Journal, 55, 1146-1168. https://doi.org/10.5465/amj.2010.0133 
Ouyang, K., Lam, W., \& Wang, W. (2015). Roles of gender and identification on abusive supervision and proactive behavior. Asia Pacific Journal of Management, 32, 671691. https://doi.org/10.1007/s10490-015-9410-7

Panaccio, A., Henderson, D. J., Liden, R. C., Wayne, S. J., \& Cao, X. (2015). Toward an Understanding of When and Why Servant Leadership Accounts for Employee ExtraRole Behaviors. Journal of Business and Psychology, 30, 657-675. https://doi.org/10.1007/s10869-014-9388-z

Pan, S. Y., \& Lin, K. J. (2018). Who Suffers When Supervisors are Unhappy? The Roles of Leader-Member Exchange and Abusive Supervision. Journal of Business Ethics, 151, 799-811. https://doi.org/10.1007/s10551-016-3247-y

Parker, S. K., \& Griffin, M. A. (2011). Understanding active psychological states: Embedding engagement in a wider nomological net and closer attention to performance. European Journal of Work and Organizational Psychology, 20, 60-67. https://doi.org/10.1080/1359432x.2010.532869

Parker, S. K., Johnson, A., Collins, C., \& Nguyen, H. (2013). Making the Most of Structural Support: Moderating Influence of Employees' Clarity and Negative Affect. Academy of Management Journal, 56, 867-892. https://doi.org/10.5465/amj.2010.0927

Parker, S. K., \& Wu, C. H. (2014). Leading for proactivity: How leaders cultivate staff who make things happen. In D. V. Day (Ed.), The Oxford handbook of leadership and organizations (pp. 380-403). Oxford, OX: Oxford University Press.

Petty, R. E., \& Cacioppo, J. T. (1986). The Elaboration Likelihood Model of Persuasion. In Communication and Persuasion (pp. 1-24). New York, NY: Springer New York. https://doi.org/10.1007/978-1-4612-4964-1_1

Podsakoff, P. M., MacKenzie, S. B., Podsakoff, N. P., \& Bachrach, D. G. (2008). Scholarly Influence in the Field of Management: A Bibliometric Analysis of the Determinants 
of University and Author Impact in the Management Literature in the Past Quarter Century. Journal of Management, 34, 641-720.

https://doi.org/10.1177/0149206308319533

Premeaux, S., \& Bedeian, A. (2003). Breaking the Silence: The Moderating Effects of SelfMonitoring in Predicting Speaking Up in the Workplace. Journal of Management Studies, 40, 1537-1562. https://doi.org/10.1111/1467-6486.00390

Raub, S., \& Liao, H. (2012). Doing the right thing without being told: Joint effects of initiative climate and general self-efficacy on employee proactive customer service performance. Journal of Applied Psychology, 97, 651-667. https://doi.org/10.1037/a0026736

Raub, S., \& Robert, C. (2010). Differential effects of empowering leadership on in-role and extra-role employee behaviors: Exploring the role of psychological empowerment and power values. Human Relations, 63, 1743-1770. https://doi.org/10.1177/0018726710365092

Rofcanin, Y., Las Heras, M., Matthijs Bal, P., Van Der Heijden, B. I., \& Erdogan, D. T. (2018). A trickle-down model of task and development i-deals. Human Relations, 71, 1508-1534. https://doi.org/10.1177/0018726717751613

Salancik, G. R., \& Pfeffer, J. (1978). A Social Information Processing Approach to Job Attitudes and Task Design. Administrative Science Quarterly, 23, 224. https://doi.org/10.2307/2392563

Schmitt, A., Den Hartog, D. N., \& Belschak, F. D. (2016). Transformational leadership and proactive work behaviour: A moderated mediation model including work engagement and job strain. Journal of Occupational and Organizational Psychology, 89, 588-610. https://doi.org/10.1111/joop.12143

Schraub, E. M., Michel, A., Shemla, M., \& Sonntag, K. (2014). The roles of leader emotion 
management and team conflict for team members' personal initiative: A multilevel perspective. European Journal of Work and Organizational Psychology, 23, 263-276. https://doi.org/10.1080/1359432X.2012.728700

Spitzmuller, M., \& Van Dyne, L. (2013). Proactive and reactive helping: Contrasting the positive consequences of different forms of helping. Journal of Organizational Behavior, 34, 560-580. https://doi.org/10.1002/job.1848

Strauss, K., Griffin, M. A., \& Rafferty, A. E. (2009). Proactivity directed toward the team and organization: The role of leadership, commitment and role-breadth self-efficacy. British Journal of Management, 20, 279-291. https://doi.org/10.1111/j.14678551.2008.00590.x

Takeuchi, R., Chen, Z., \& Cheung, S. Y. (2012). Applying uncertainty management theory to employee voice behavior: An integrative investigation. Personnel Psychology, 65, 283-323. https://doi.org/10.1111/j.1744-6570.2012.01247.x

Tangirala, S., \& Ramanujam, R. (2012). Ask and you shall hear (but not always): Examinng the relationship between consultation and employee voice. Personnel Psychology, 65, 251-282. https://doi.org/10.1111/j.1744-6570.2012.01248.x

Tepper, B. J., Simon, L., \& Park, H. M. (2017). Abusive Supervision. Annual Review of Organizational Psychology and Organizational Behavior, 4, 123-152. https://doi.org/10.1146/annurev-orgpsych-041015-062539

Tett, R. P., \& Burnett, D. D. (2003). A personality trait-based interactionist model of job performance. Journal of Applied Psychology, 88, 500-517. https://doi.org/10.1037/0021-9010.88.3.500

Tröster, C., \& Van Knippenberg, D. (2012). Leader openness, nationality dissimilarity, and voice in multinational management teams. Journal of International Business Studies, 43, 591-613. https://doi.org/10.1057/jibs.2012.15 
Tucker, S., Chmiel, N., Turner, N., Hershcovis, M. S., \& Stride, C. B. (2008). Perceived Organizational Support for Safety and Employee Safety Voice: The Mediating Role of Coworker Support for Safety. Journal of Occupational Health Psychology, 13, 319-330. https://doi.org/10.1037/1076-8998.13.4.319

Van Dyne, L., Kamdar, D., \& Joireman, J. (2008). In-Role Perceptions Buffer the Negative Impact of Low LMX on Helping and Enhance the Positive Impact of High LMX on Voice. Journal of Applied Psychology, 93, 1195-1207. https://doi.org/10.1037/00219010.93.6.1195

Van Kleef, G. A., De Dreu, C. K. W., \& Manstead, A. S. R. (2010). An Interpersonal Approach to Emotion in Social Decision Making. Advances in Experimental Social Psychology, 42, 45-96. https://doi.org/10.1016/S0065-2601(10)42002-X

Venkataramani, V., \& Tangirala, S. (2010). When and Why Do Central Employees Speak Up? An Examination of Mediating and Moderating Variables. Journal of Applied Psychology, 95, 582-591. https://doi.org/10.1037/a0018315

Wallace, J. C., Butts, M. M., Johnson, P. D., Stevens, F. G., \& Smith, M. B. (2016). A Multilevel Model of Employee Innovation. Journal of Management, 42, 982-1004. https://doi.org/10.1177/0149206313506462

Walumbwa, F. O., \& Hartnell, C. A. (2011). Understanding transformational leadershipemployee performance links: The role of relational identification and self-efficacy. Journal of Occupational and Organizational Psychology, 84, 153-172. https://doi.org/10.1348/096317910X485818

Walumbwa, F. O., \& Schaubroeck, J. (2009). Leader Personality Traits and Employee Voice Behavior: Mediating Roles of Ethical Leadership and Work Group Psychological Safety. Journal of Applied Psychology, 94, 1275-1286. https://doi.org/10.1037/a0015848 
Ward, A. K., Ravlin, E. C., Klaas, B. S., Ployhart, R. E., \& Buchan, N. R. (2016). When do high-context communicators speak up? Exploring contextual communication orientation and employee voice. Journal of Applied Psychology, 101, 1498-1511. https://doi.org/10.1037/ap10000144

Wei, X., Zhang, Z. X., \& Chen, X. P. (2015). I will speak up if my voice is socially desirable: A moderated mediating process of promotive versus prohibitive voice. Journal of Applied Psychology, 100, 1641-1652. https://doi.org/10.1037/a0039046

Weiss, M., Kolbe, M., Grote, G., Spahn, D. R., \& Grande, B. (2017). Why didn’t you say something? Effects of after-event reviews on voice behaviour and hierarchy beliefs in multi-professional action teams. European Journal of Work and Organizational Psychology, 26, 66-80.

West, M. A., Hirst, G., Richter, A., \& Shipton, H. (2004). Twelve steps to heaven: Successfully managing change through developing innovative teams. European Journal of Work and Organizational Psychology, 13, 269-299. https://doi.org/10.1080/13594320444000092

Wu, C. H., \& Li, W. (2017). Individual differences in proactivity. In S. K. Parker, \& U. K. Bindl (Eds.), Proactivity at Work (pp. 226-257). Oxford, OX: Routledge.

Wu, C. H., \& Parker, S. K. (2017). The Role of Leader Support in Facilitating Proactive Work Behavior: A Perspective From Attachment Theory. Journal of Management, 43, 1025-1049. https://doi.org/10.1177/0149206314544745

Wu, C. H., Parker, S. K., \& de Jong, J. P. J. (2014). Need for Cognition as an Antecedent of Individual Innovation Behavior. Journal of Management, 40, 1511-1534. https://doi.org/10.1177/0149206311429862

Wu, C. H., Liu, J., Kwan, H. K., \& Lee, C. (2016). Why and when workplace ostracism inhibits organizational citizenship behaviors: An organizational identification 
perspective. Journal of Applied Psychology, 101, 362-378.

https://doi.org/10.1037/ap10000063

Wu, X., Kwan, H. K., Wu, L. Z., \& Ma, J. (2018). The Effect of Workplace Negative Gossip on Employee Proactive Behavior in China: The Moderating Role of Traditionality. Journal of Business Ethics, 148, 801-815. https://doi.org/10.1007/s10551-015-3006-5

Yang, F. (2017). Better understanding the perceptions of organizational politics: its impact under different types of work unit structure. European Journal of Work and Organizational Psychology, 26, 250-262. https://doi.org/10.1080/1359432X.2016.1251417

Yoo, J. (2017). Customer power and frontline employee voice behavior: Mediating roles of psychological empowerment. European Journal of Marketing, 51, 238-256. https://doi.org/10.1108/EJM-07-2015-0477

Yuan, F., \& Woodman, R. W. (2010). Innovative behavior in the workplace: The role of performance and image outcome expectations. Academy of Management Journal, 53, 323-342. https://doi.org/10.5465/AMJ.2010.49388995

Zhang, X. A., Li, N., \& Brad Harris, T. (2015). Putting non-work ties to work: The case of guanxi in supervisor-subordinate relationships. Leadership Quarterly, 26, 37-54. https://doi.org/10.1016/j.leaqua.2014.04.008

Zhang, Y., Huai, M. Y., \& Xie, Y. H. (2015). Paternalistic leadership and employee voice in China: A dual process model. Leadership Quarterly, 26, 25-36. https://doi.org/10.1016/j.leaqua.2014.01.002

Zhu, W., He, H., Treviño, L. K., Chao, M. M., \& Wang, W. (2015). Ethical leadership and follower voice and performance: The role of follower identifications and entity morality beliefs. Leadership Quarterly, 26, 702-718. https://doi.org/10.1016/j.leaqua.2015.01.004 


\section{Online Supplement Appendix1. List of Included Journals.}

1. Administrative Science Quarterly

2. Academy of Management Journal

3. British Journal of Management

4. European Journal of Work and Organizational Psychology

5. Human Relations

6. Human Resource Management

7. Journal of Applied Psychology

8. Journal of Business Ethics

9. Journal of Business and Psychology

10. Journal of Business Research

11. Journal of Business Venturing

12. Journal of International Business Studies

13. Journal of Management

14. Journal of Management Studies

15. Journal of Occupational and Organizational Psychology

16. Journal of Organizational Behavior

17. Journal of Vocational Behavior

18. Leadership Quarterly

19. Management and Organization Review

20. Organizational Behavior and Human Decision Processes

21. Organizational Research Method

22. Organization Science

23. Personnel Psychology

24. Strategic Management Journal 
Online Supplement Figure 1. Findings of Social Context Factors as Antecedents of Proactive Behavior

Insert Figure 1 here ${ }^{1}$

${ }^{1}$ Findings are organized as "theme - specific social context factor - ambient or discretionary - outcome proactive behavior - identified mediation mechanism". In the bracket is the corresponding paper. For example, (Wang, 2010, JAP) means that this finding is from the paper whose first author is Wang and that was published in JAP in 2010. 
Online Supplement Figure 2. Leader-related Factors as Antecedents of Proactivity

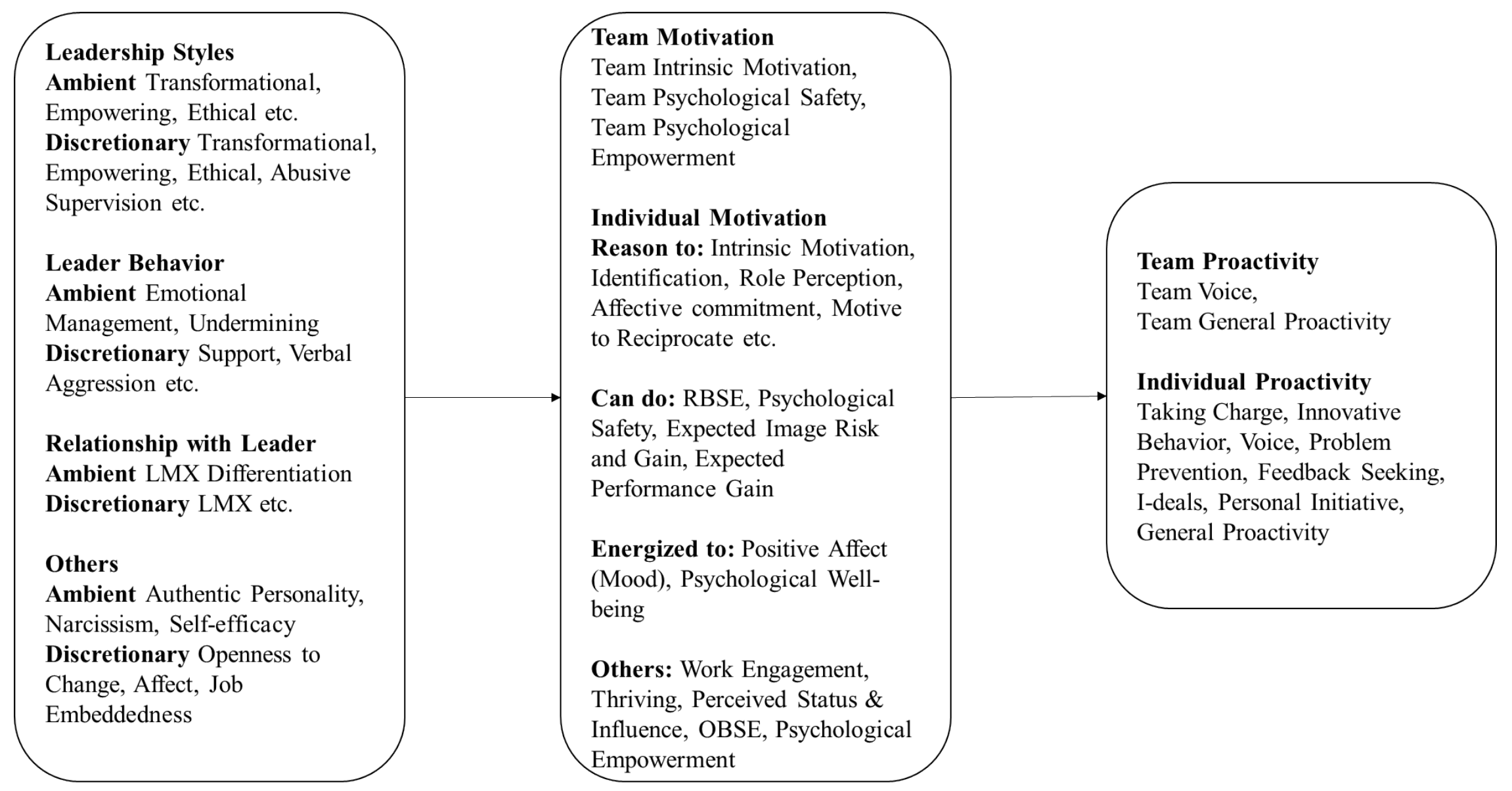


Online Supplement Figure 3. Team-related Factors as Antecedents of Proactivity

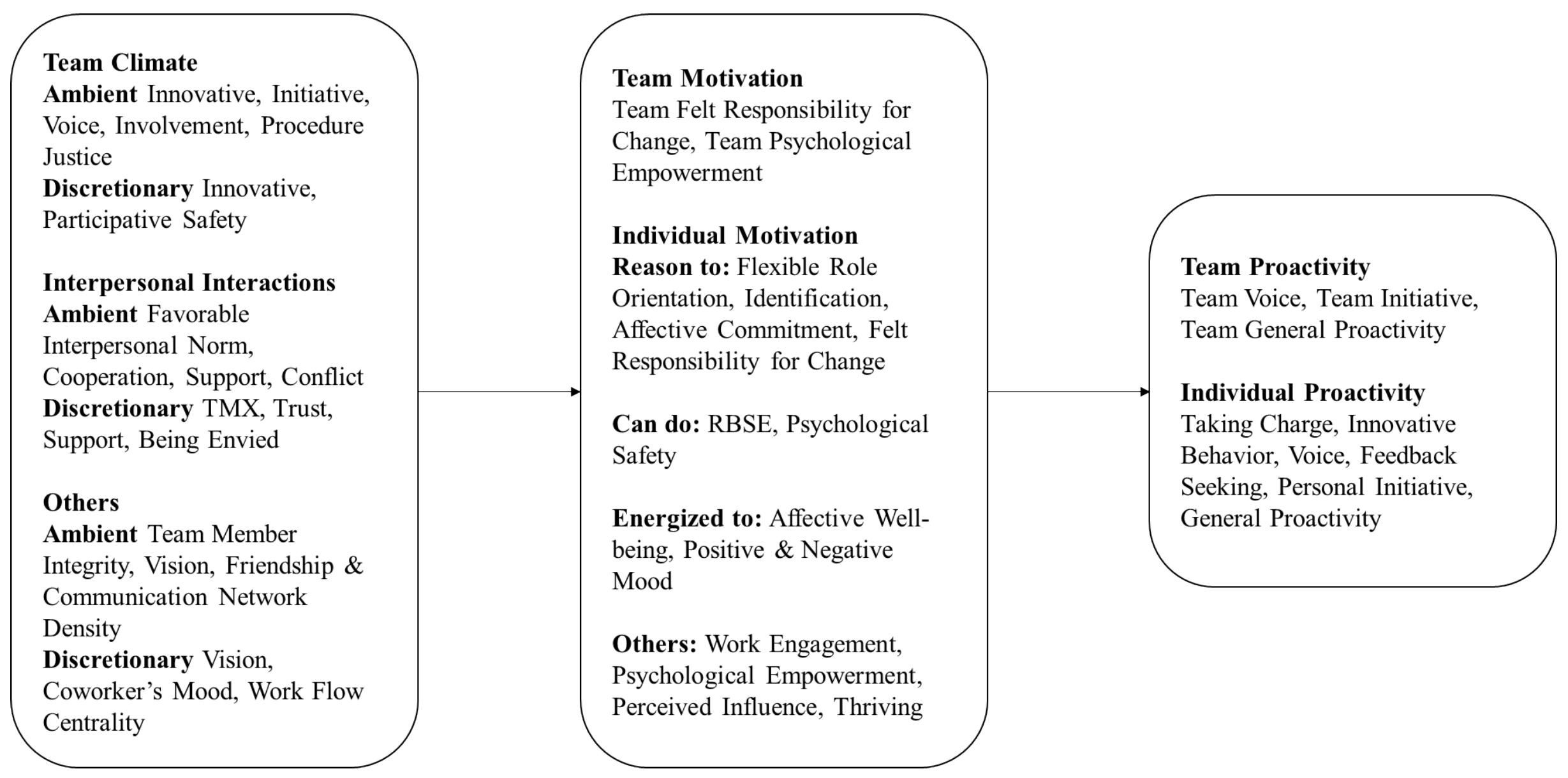


Online Supplement Figure 4. Organization-related Factors as Antecedents of Proactivity

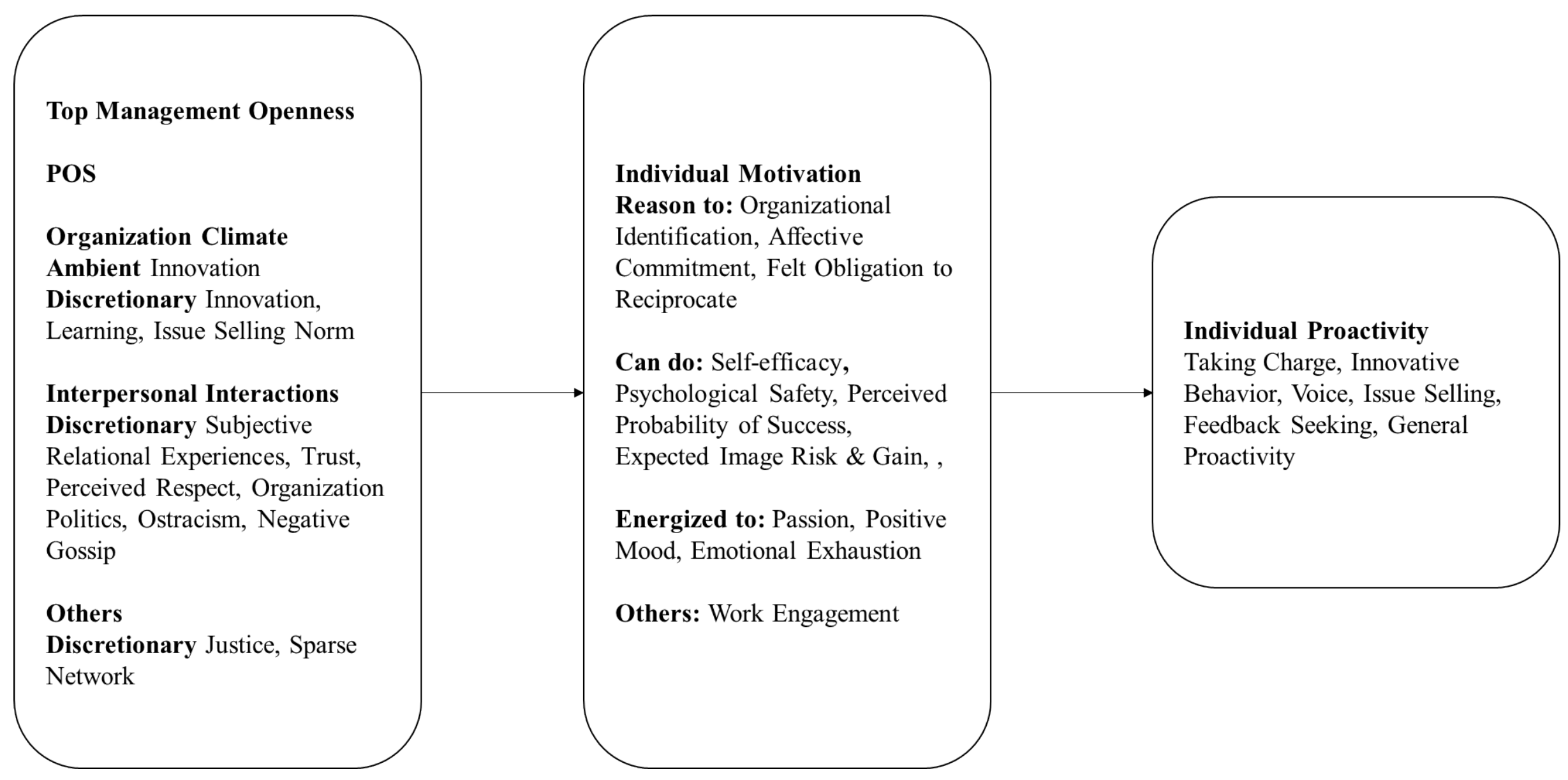


Online Supplement Figure 5. The Integrative Model Showing the Number of Studies for Each Key Pathway ${ }^{2}$

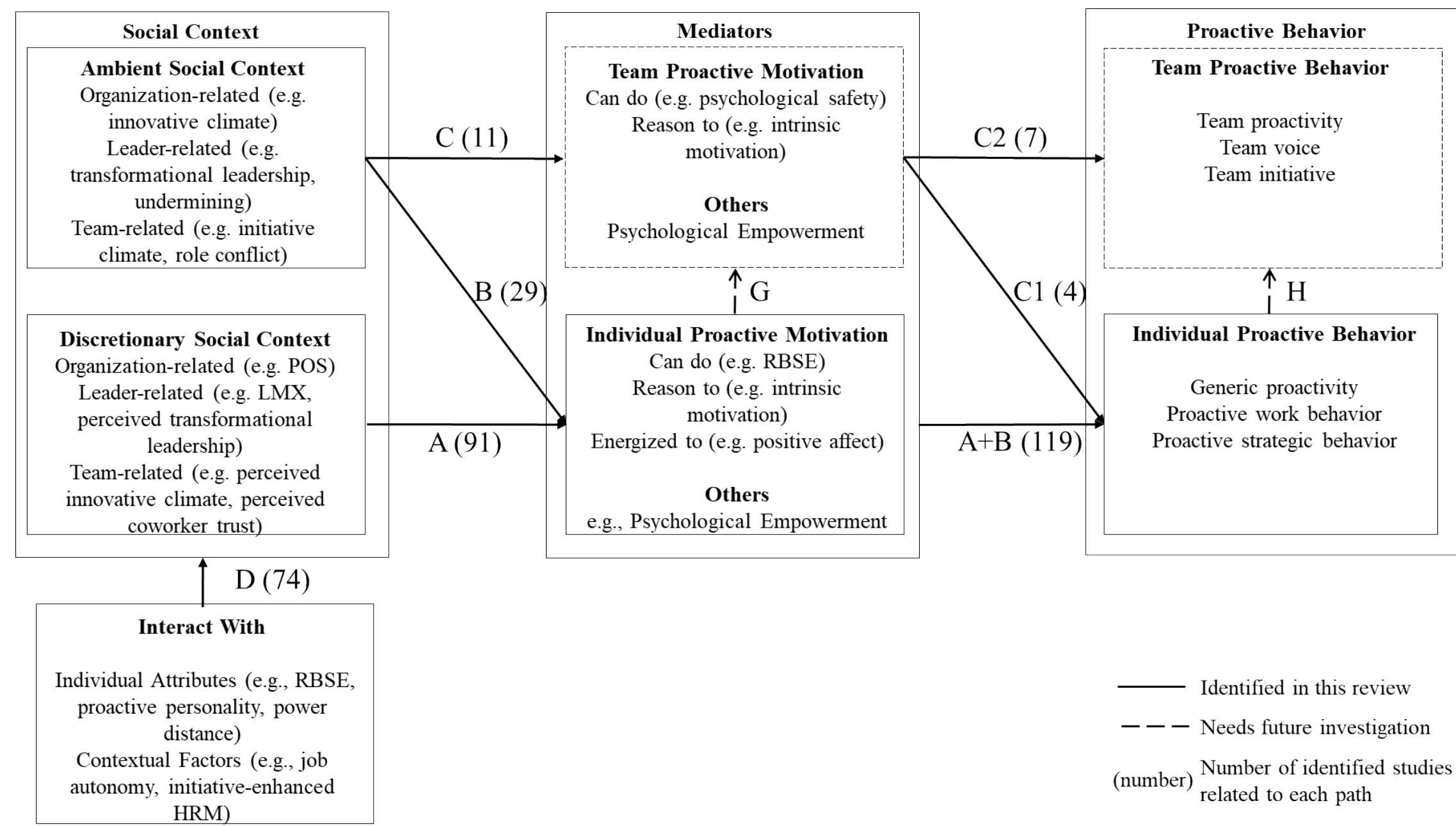

${ }^{2}$ The numbers in all brackets sum up to more than 152 because some studies examined multiple paths simultaneously. 


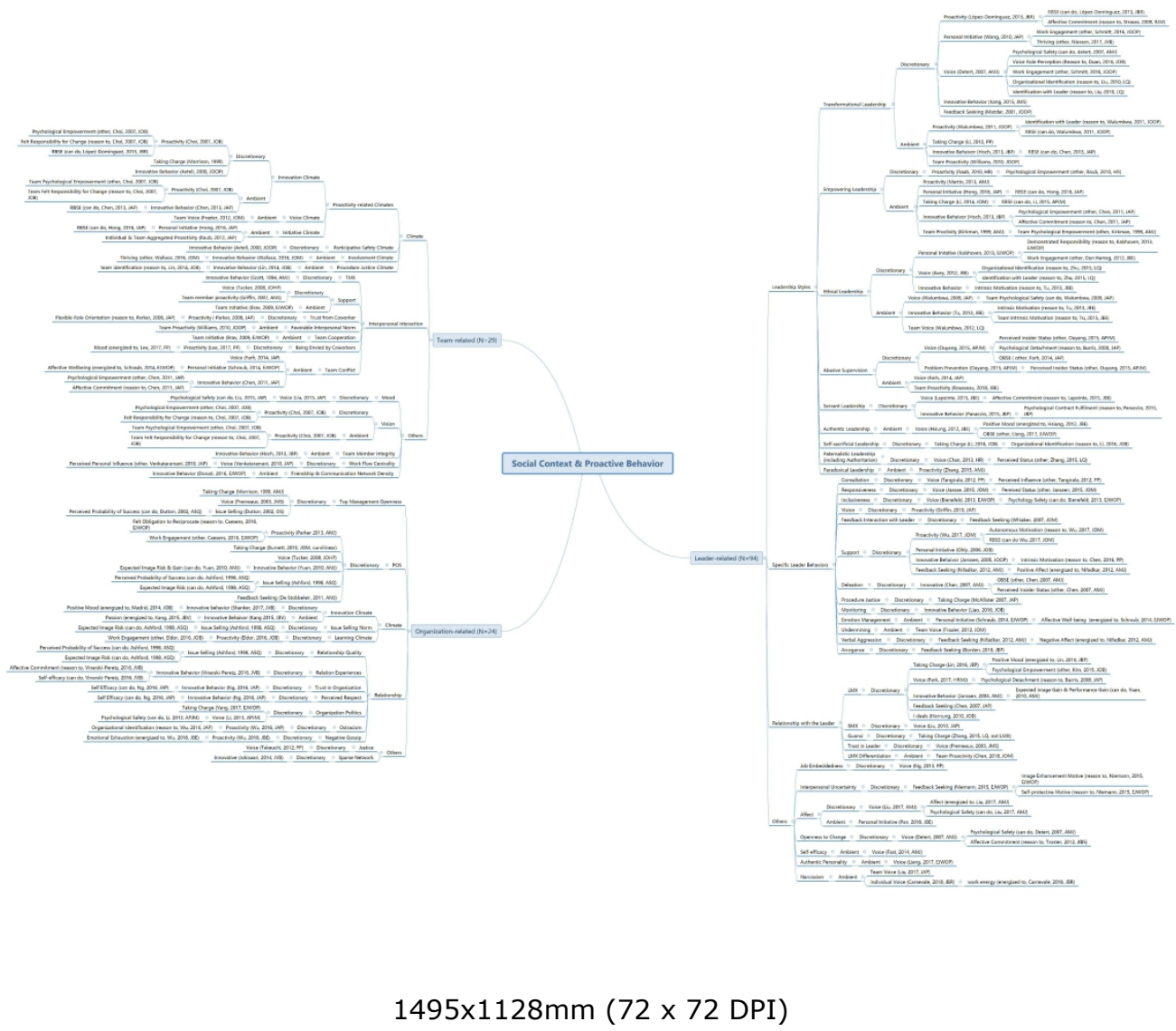

$1495 \times 1128 \mathrm{~mm}(72 \times 72 \mathrm{DPI})$

http://mc.manuscriptcentral.com/job 